\title{
Usability and acceptability of technology for community-dwelling older adults with mild cognitive impairment and dementia: a systematic literature review
}

This article was published in the following Dove Press journal:

Clinical Interventions in Aging

\author{
Torhild Holthe \\ Liv Halvorsrud \\ Dag Karterud \\ Kari-Anne Hoel \\ Anne Lund \\ Faculty of Health, Oslo Metropolitan \\ University, Oslo, Norway
}

Background: The objective of this review was to obtain an overview of the technologies that have been explored with older adults with mild cognitive impairment and dementia (MCI/D), current knowledge on the usability and acceptability of such technologies, and how people with $\mathrm{MCI} / \mathrm{D}$ and their family carers (FCs) were involved in these studies.

Materials and methods: Primary studies published between 2007 and 2017 that explored the use of technologies for community-dwelling people with $\mathrm{MCI} / \mathrm{D}$ were identified through five databases: MEDLINE, PsycINFO, Embase, AMED, and CINAHL. Twenty-nine out of 359 papers met the criteria for eligibility. We used the Mixed Methods Appraisal Tool for quality assessment.

Results: A wide range of technologies was presented in the 29 studies, sorted into four domains: 1) safe walking indoors and outdoors; 2) safe living; 3) independent living; and 4) entertainment and social communication. The current state of knowledge regarding usability and acceptability reveals that even if researchers are aware of these concepts and intend to measure usability and acceptability, they seem difficult to assess. Terms such as "user friendliness" and "acceptance" were used frequently. User participation in the 29 studies was high. Persons with MCI/D, FCs, and staff/other older adults were involved in focus groups, workshops, and interviews as part of the preimplementation process.

Conclusion: Research regarding technologies to support people with MCI/D seems optimistic, and a wide range of technologies has been evaluated in homes with people with MCI/D and their FCs. A major finding was the importance of including people with MCI/D and their FCs in research, in order to learn about required design features to enhance usability and acceptability. Surprisingly, very few studies reported on the consequences of technology use with regard to quality of life, occupational performance, or human dignity.

Keywords: technology, Alzheimer's disease, coping, aging in place, safety, quality of life, dignity

\section{Introduction}

The aging society is described as a grand societal challenge, ${ }^{1}$ and access to technology is one important strategy in future health-care services. ${ }^{2}$ Older people often have multiple and chronic diseases, often requiring extensive care services. The prevalence of Alzheimer's disease or related dementias extends to nearly 44 million people worldwide and is most common in Western Europe. ${ }^{3}$ Dementia is a neurodegenerative condition due to disease of the brain, of a chronic or progressive
Correspondence: Torhild Holthe Faculty of Health, Oslo Metropolitan University, PO Box 4, St Olavs plass, 0130 Oslo, Norway

Tel +47 23676789

Mobile +4791134088

Email torhild.holthe@oslomet.no 
nature, that influences cognitive, psychological, behavioral, and motor skills, having consequences for quality of life (QoL) and everyday living competency. ${ }^{4}$ The ICD-10 presents four criteria for dementia: 1) impaired memory; 2) clear consciousness; 3 ) impaired emotional control, motivation or social behavior; and 4) the condition must have lasted for at least 6 months. Dementia is divided into mild, moderate, and severe stages, depending on the extent to which the condition influences everyday living. ${ }^{5}$

Mild cognitive impairment (MCI) encompasses attention, concentration, memory, comprehension, reasoning, and problem solving. According to Winblad et al (2004), MCI is a useful term as both a clinical and a research entity ${ }^{6}$ and is usually perceived as the preclinical stage of dementia. However, MCI may be stable and occasionally reversible. ${ }^{7}$ The risk of mortality seems to be high for all types. Hedman et al (2013) studied patterns of functioning in older adults with MCI and found that they exhibited different patterns: stable, fluctuating, descending, or ascending. The patterns may change over time, and thus individual support is needed. ${ }^{8}$

Technologies, such as digital calendars, speaking watches, and Global Positioning System (GPS), have been shown to support time orientation, memory, and safety in people with mild cognitive impairment/dementia (MCI/D). ${ }^{9-12}$ Technology may have the potential to support a person's occupational performance, meaning helping out "the actual execution or carrying out of an occupation" (p. 26), ${ }^{13}$ and facilitate a good and dignified life, reducing the pressure on family carers (FCs) and the need for community care services. Dignified lives for older adults, defined by Heggestad ${ }^{14}$ refers to Jacobson's definition (2009) of human dignity as "the intrinsic dignity that belongs to every human being," 14 are increasingly discussed in health-care services. Human dignity is closely related to human identity. Being a technology user has implications for identity. ${ }^{15}$ If a person finds the technology ugly, not user friendly, or not compatible with his or her lifestyle, the device will hardly be accepted.

Access to technology that addresses a need is anticipated to have an impact on QoL, which may be defined as:

an individual's perception of their position in life in the context of the culture and value systems in which they live and in relation to their goals, expectations, and standards and concerns. ${ }^{16}$

However, it is a prerequisite that the technology matches the needs of the user and is accepted as an aid and incorporated into everyday living.
Eicher et al (2017) claimed that good usability and user acceptability encourage patients to engage in the training and coping with the new technology. Therefore, it is interesting to investigate usability and acceptability in technology studies. ${ }^{17}$ "Usability" is defined as "the extent to which a product can be used by specified users to achieve specified goals with effectiveness, efficiency, and satisfaction in a specified context of use," 18 while "acceptability" is defined as "the degree of primary users' predisposition to carry out daily activities using the intended device" (p. 73). ${ }^{19}$ Arthur (2009, p. 29) defined acceptability for technology as being a "means to fulfill a human purpose, ${ }^{20}$ and stated that technology may be a method, process, or device.

It has been argued that technology mainly has been provided to safeguard older people with $\mathrm{MCI} / \mathrm{D}$ at home, with less attention given to technology for assisting people in living a good life. ${ }^{21}$ Kenigsberg et al (2016) state that assistive technology such as information and communication technologies can provide useful information for assisting older adults with dementia, if tailored to the end users' capacities. However, there is still a need to educate health staff to assess users' capacities, preferences, and motivation for using technology and to evaluate the information and communication technologies to better inform technology developers as to user needs and performance styles. ${ }^{22}$ In addition, an important factor concerns creating a supportive network for the user as part of the technology implementation. ${ }^{23}$

The criteria for successfully matching technology to a person's needs and capacities are various. They include health staff's assessment skills in revealing the needs, resources, challenges, and capacities of the user, their ability to successfully individualize the technology to the user's needs and context, and the user's acceptance of technology. An additional issue is the usability of the chosen technology: its maturity, robustness, and predictability as a sustainable solution for the user. The organization of community services and access to proper technology support are also important. ${ }^{24}$

Several pilot projects (Enable, ${ }^{64} \mathrm{Safe} @$ home, ${ }^{65} \mathrm{ACTION},{ }^{66}$ COGKNOW, ${ }^{67}$ Rosetta, ${ }^{27}$ Casas,${ }^{68}$ and NOCTURNAL ${ }^{69}$ ) have focused on the usability of different types of technologies for older people with dementia and MCI in test laboratories or at home, and found that such technology may be of benefit for both the person with MCI/D and their FC. However, all of these projects concluded that further research is needed, in particular studies that include the users' perspectives on usability and acceptability.

This systematic review aims to investigate primary studies that include people with $\mathrm{MCI} / \mathrm{D}$ in technology trials. 
As recommended for systematic reviews, we outlined three research questions for our literature search: ${ }^{25}$

- What types of technologies have been explored with home-dwelling older adults with MCI/D?

- What is the current knowledge about the usability and acceptability of such technologies with regard to occupational performance, QoL, and human dignity for independent living?

- How are users involved in the reviewed technology studies?

\section{Material and methods}

This systematic review was prospectively registered in PROSPERO (reg 42017058789, May 7, 2017).

\section{Data sources and search strategy}

We searched PROSPERO (www.prospero.org) to check whether others had performed a recent literature review on this topic, before starting the literature search. However, we did not find any earlier or ongoing reviews on this topic.

\section{Eligibility criteria}

The review aimed to identify peer-reviewed primary studies concerning technologies that had been developed and/or explored with home-dwelling older adults with $\mathrm{MCI} / \mathrm{D}$ above 65 years of age. The search included studies from January 2007 to June 2017. Papers in the English language were included.

\section{Inclusion criteria}

- Primary studies on technology for older people with $\mathrm{MCI} / \mathrm{D}$.

- The title and/or keywords included a type or types of technology; this could be the name of a device or technology mentioned as a system, eg, smart-home system, ambient assistive living (AAL), or artificial intelligence (AI).

- The title and/or keywords included the population (mild) cognitive impairment, dementia, or early phase of dementia, or Alzheimer's disease.

\section{Exclusion criteria}

- Not target population (MCI/D)

- Not primary study

- Laboratory studies

- Not technology for support of everyday living

- Long-term care/nursing home

- Conference paper, editorial, protocol

- Review articles/meta-analyses

- Books, book chapters.

\section{Information sources}

Five databases were searched for studies: MEDLINE, PsycINFO, Embase, AMED, and CINAHL (Table 1). A systematic literature search must make use of search words that are valid in the thesaurus of each database, eg, Medical Subject Headings terms. ${ }^{25}$

\section{Search strategy}

The strategy was to use the Medical Subject Headings terms related to each database. Table 2 shows an example of the search strategy from the CINAHL database.

\section{Study selection}

Altogether, 359 titles were identified in this literature search. After checking for duplicates, the number decreased to 298. Ovid Auto Updates were checked for relevant titles after the search date June 20, 2016 and until June 17, 2017. One more paper was of interest; however, the full text was not found. Another two papers were detected through other sources; one was sent to us from an earlier project colleague ${ }^{34}$ and the other was found in the first author's personal archive of papers on technology and dementia. ${ }^{32}$ Thus, the review consisted of 301 papers to be appraised by all five authors, three nurses, and two occupational therapists. Four of the authors completed Steps 1 and 2 in the review process before the fifth author (a nurse) took part from Step 3 onward.

\section{Review process}

The review process had four steps:

- Step 1. Screening titles: The pile with 301 titles was divided into two piles. Two teams, each consisting of one nurse and one occupational therapist, screened titles and keywords for relevance separately. Then, the two authors from each team met and compared their screening results and agreed upon which titles to include and exclude. Thereafter, the two teams met and presented their screening results and elaborated an overview of which titles to include for the next step. In this first screening step, 188 titles were excluded.

- Step 2. Reading abstracts: The two teams read the abstracts of the selected papers and excluded papers not relevant to the research questions. An additional 26 titles were excluded owing to being reviews, editorials, conference papers, nonintervention studies, studies not involving $\mathrm{MCI} / \mathrm{D}$, nursing home studies, or books and book chapters. At the end of this step, 87 titles remained.

- Step 3. Reading full-text articles: The first author transferred the 87 titles eligible for full-text review into an 
Table I Databases and search words for identifying literature for review, June 20, 2016

\begin{tabular}{|c|c|c|}
\hline Database & Search terms & $\begin{array}{l}\text { No of text } \\
\text { results }\end{array}$ \\
\hline MEDLINE & $\begin{array}{l}\text { AAL, ai, aid,* alzheimer disease, alzheimer,* ambient, ambient assisted living, artificial, artificial intelligence, } \\
\text { assisted, assisted living facilities, assistive, automation, autonom,* body, cognitive, consumer participation, daily, } \\
\text { daily living, dement,* dementia, dementia friendly, dementia, multi-infarct dementia, vascular, device,* digni,* } \\
\text { diseas,* disorder,* everyday, friendly, frontotemporal lobar degeneration, health, health related quality of life, } \\
\text { home, home automation, hrqol, impair,* intelligence, lewy, lewy body diseas,* lewy body disease, life, living, man- } \\
\text { machine systems, mci, memory, memory disorder,* memory disorders, memory impair,* mild, mild cognitive } \\
\text { impair,* mild cognitive impairment, of participat,* patient satisfaction, personal autonomy, personhood, principle- } \\
\text { based ethics, qol, quality, quality of life, related, residential facilities, satisf,* self-help, self-help devices, sensor, } \\
\text { sensor technology, sensor-based, sensor-based technology, smart-home, technology, welfare, well-being, wellbeing }\end{array}$ & 235 \\
\hline PsyclNFO & $\begin{array}{l}\text { AAL, Al, aid,* alzheimer's disease, alzheimer,* ambient, ambient assisted living, artificial, artificial intelligence, } \\
\text { assisted, assistive, assistive technology, automation, autonom,* autonomy, body, client participation, cognitive, } \\
\text { cognitive impairment, daily, daily living, dement,* dementia, dementia friendly, dementia with lewy bodies, device,* } \\
\text { digni,* dignity, diseas,* disorder,* everyday, friendly, health, health related quality of life, home, home automation, } \\
\text { hrqol, human computer interaction, human machine systems, impair,* independence (personality), intelligence, } \\
\text { involvement, lewy, lewy body diseas,* life, life satisfaction, living, mci, memory, memory disorder,* memory } \\
\text { disorders, memory impair,* mild, mild cognitive impair,* of participat,* qol, quality, quality of life, related, respect, } \\
\text { satisf,* satisfaction, self-help, sensor, sensor technology, sensor-based, sensor-based technology, smart-home, } \\
\text { social behavior, technology, vascular dementia, welfare, well being, well-being, wellbeing }\end{array}$ & 93 \\
\hline Embase & Alzheimer disease, artificial intelligence, dementia, mild cognitive impairment, quality of life & 18 \\
\hline AMED & Alzheimers disease, assistive devices, dementia, disability aids, mild cognitive impairment & I \\
\hline CINAHL $\ddagger$ & $\begin{array}{l}\text { AAL, ai, aid,* ambient assisted living, IN artificial, artificial intelligence, TC assistive, AF automation, assisted living, } \\
\text { cogn,* cognition disorders, cognitive device,* disorders, home, home automation, man-machine systems, mci, } \\
\text { mild cognitive impairment, self-help, self-help devices, sensor, sensor technology, sensor-based, DH sensor-based } \\
\text { technology, smart-home, technology, technolog,* welfare }\end{array}$ & 15 \\
\hline Total & & 362 \\
\hline
\end{tabular}

Note: ₹Search date: September 27, 2016.

Excel file, with columns for data about the aim of studies, number of participants and sample characteristics, study design, types of technologies, and findings regarding usability, effectiveness of technology, and acceptability reported by people with $\mathrm{MCI} / \mathrm{D}$ and their FCs. The five authors individually read on-fifth of the articles and filled in the data abstraction Excel file. At this step, another 58 papers were excluded for reasons of: not being primary studies (26 studies), being reviews (14 studies), not focusing on technology usability and acceptance (seven

Table 2 Example of search strategy

\begin{tabular}{lll}
\hline Search ID & Search terms & Results \\
\hline SI & mci OR mild cognitive impairment & 2,601 \\
S2 & (MH “Assisted Living”) & 2,146 \\
S3 & SI AND S2 & 10 \\
S4 & (MH “Cognition Disorders”) OR & 14,274 \\
& "cognitive disorders” & \\
S5 & S2 AND S4 & 31 \\
S6 & (MH “Technology”) OR “technology*” & 81,053 \\
S7 & S5 AND S6 & $\mathrm{I}$ \\
S8 & S2 AND S6 & 70 \\
S9 & cogn* & 73,515 \\
S10 & S8 AND S9 & 6 \\
SII & S3 OR SI0 & 15 \\
\hline
\end{tabular}

studies), participants not having MCI/D (eight studies), and being unable to find the full text of a paper (three studies) (Figure 1). The full-text review ended up with 29 papers.

- Step 4. Out of the pool of five authors, two and two read the same half of the 29 papers. The first author read all the selected papers. We conducted a quality assessment of papers using the Mixed Methods Appraisal Tool $(\mathrm{MMAT})^{26}$ for systematic mixed methods review. Only papers that clearly stated having a mixed method design were sorted under mixed methods.

\section{Quality assessment of papers}

The MMAT for systematic mixed methods review was used to assess the quality of the papers selected for this review. The MMAT has five categories of study design: 1) qualitative; 2) quantitative randomized controlled trials; 3) quantitative nonrandomized; 4) quantitative descriptive; and 5) mixed methods. The MMAT permits the researcher to concomitantly appraise and describe the methodological quality for qualitative, quantitative, and mixed method studies, defined using specific methodological quality criteria. ${ }^{26}$ Six of the 


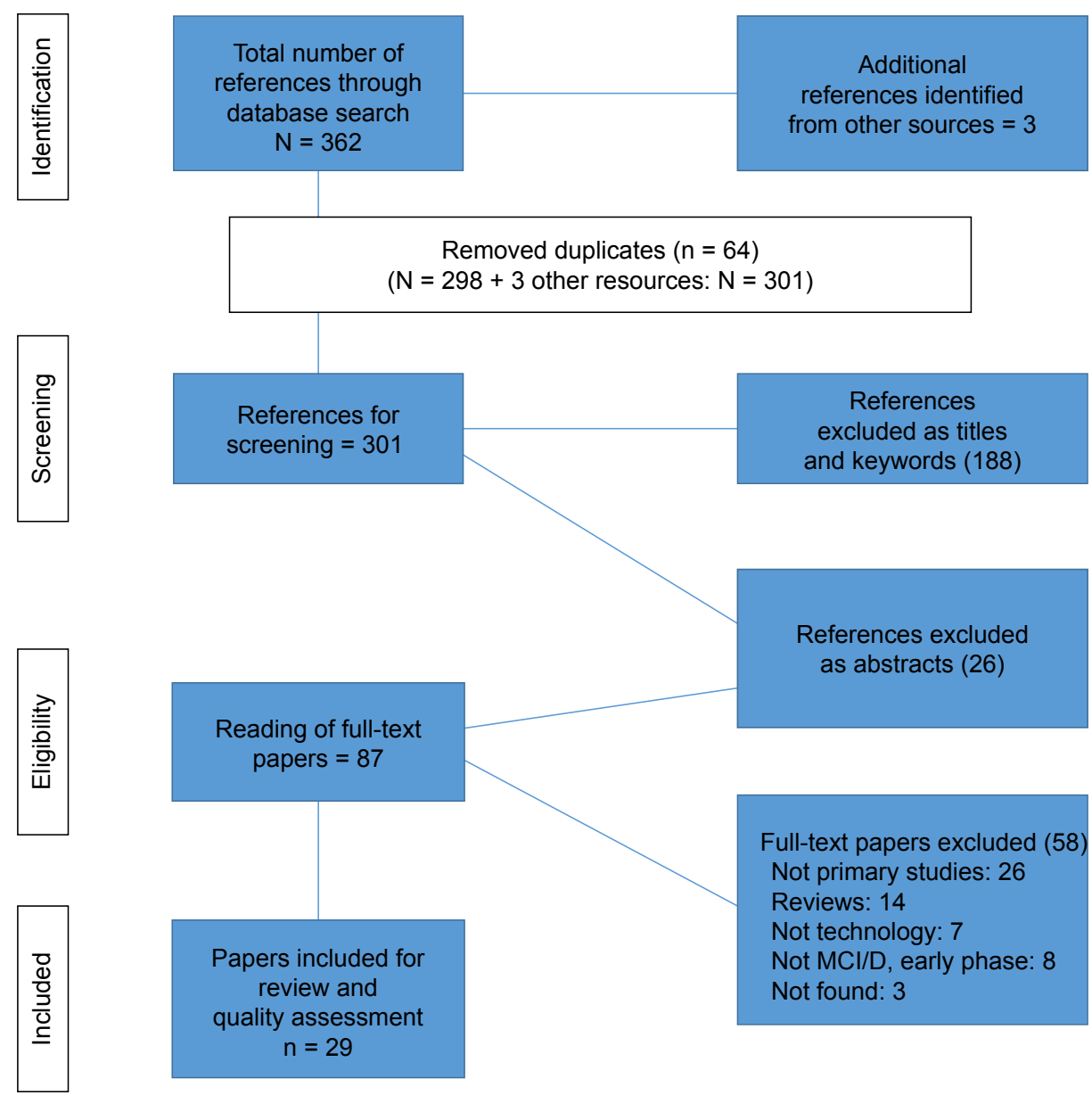

Figure I PRISMA flowchart for selection of papers.

Note: Adapted from Moher D, Liberati A, Tetzlaff J, Altman DG; PRISMA Group. Reprint-Preferred Reporting Items for Systematic Reviews and Meta-Analyses: the PRISMA statement. Phys Ther. 2009;89(9):873-880. Creative Commons license and disclaimer available from: http://creativecommons.org/licenses/by/4.0/legalcode. ${ }^{25}$

Abbreviations: PRISMA, Preferred Reporting Items for Systematic Reviews and Meta-Analyses; MCI/D, mild cognitive impairment/dementia.

29 reviewed papers were rated as high-quality studies, meeting all the quality criteria (four stars); 11 were rated with three stars (meeting $75 \%$ of the quality criteria); seven with two stars (meeting half of the quality criteria); and five with one star (meeting $25 \%$ of the quality criteria) (Table 3 ). This allowed us to overview by the quality of the selected studies and provided the opportunity to exclude studies with the lowest quality from the review, or to contrast high-quality studies with low-quality studies. However, in our review, the aim was to obtain an overview of what technologies have been explored among people with MCI/D and their FCs. Therefore, no studies were excluded because of a lack of quality.

\section{Preparing data abstraction findings for presentation}

The following data characteristics were recorded in the Excel files: author, year, country, MMAT score, title; type of technology, purpose of technology; number of participants (MCI/D + FCs/staff); design according to MMAT, duration of intervention, usability/acceptability; impact on QoL, occupational performance, and human dignity; and implications for clinical practice.

According to the template for this paper, data abstraction is presented in three steps: quantitative synthesis, qualitative synthesis, and study designs for user involvement in the 29 reviewed studies.

\section{Results}

The aim of this review was three-fold: to obtain an overview of the kind of technologies that were evaluated with people with MCI/D and FCs in the past decade (2007-2017), and how these users rated the usability and acceptability of such technologies. Further, we wanted to learn about how people with $\mathrm{MCI} / \mathrm{D}$ and FCs had been involved in the studies reviewed. 


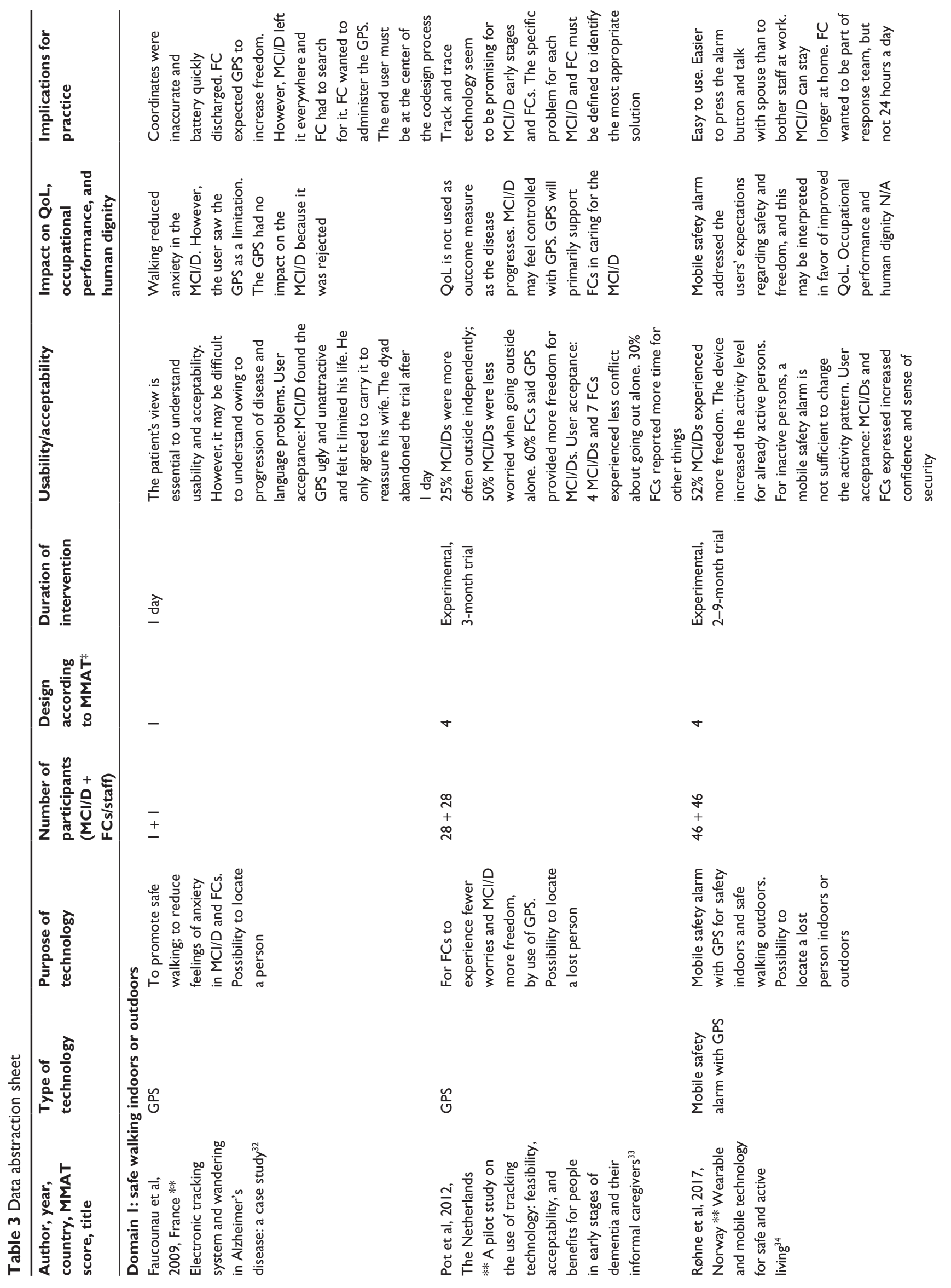



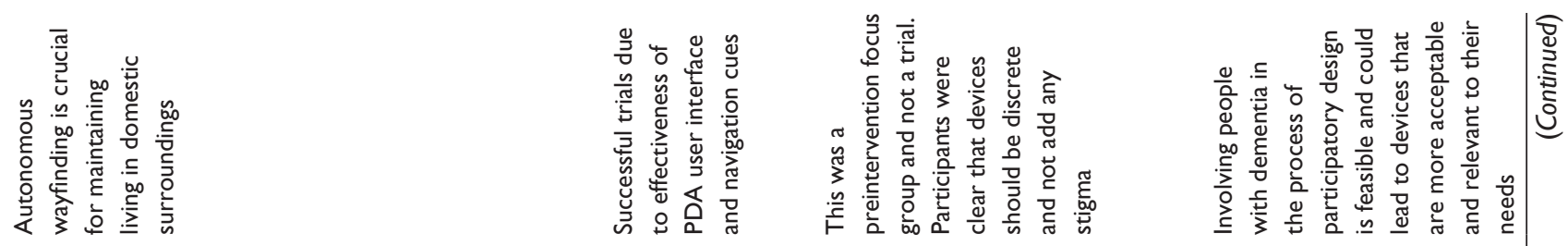

$\frac{5}{z}$

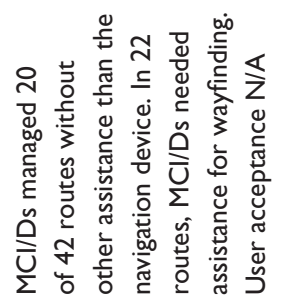

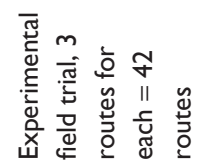

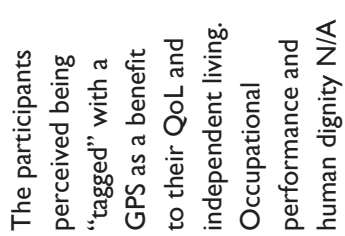

$\underline{\underline{z}}$

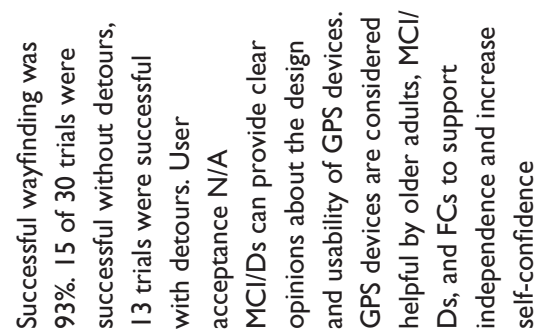

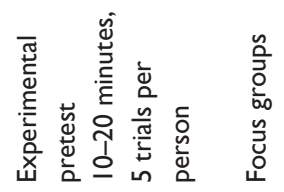

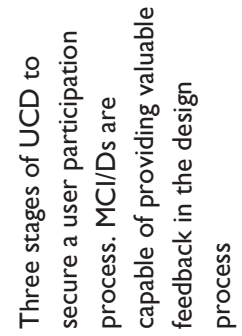

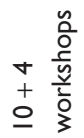

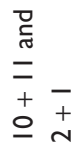

$\pm$

$\circ$

$\infty$
+
$\simeq$

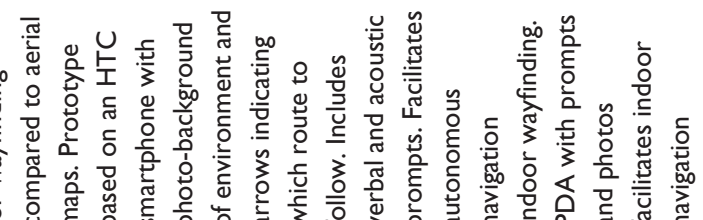
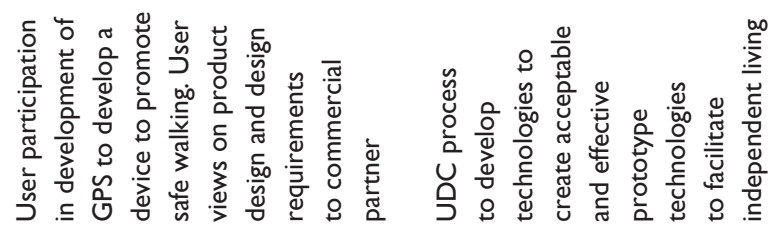

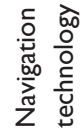

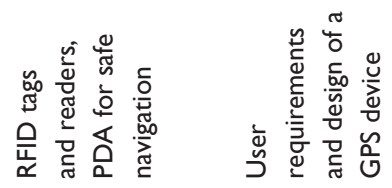

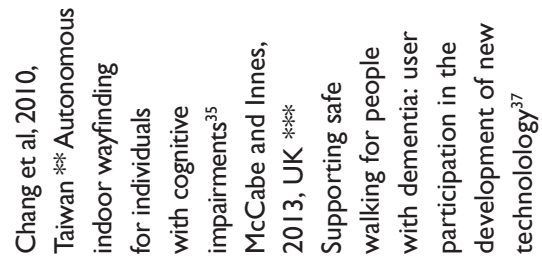

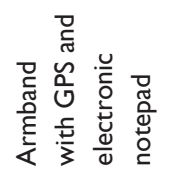

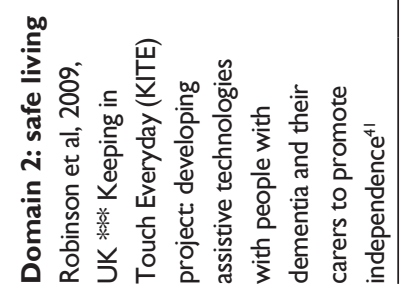

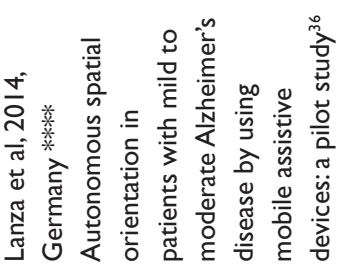




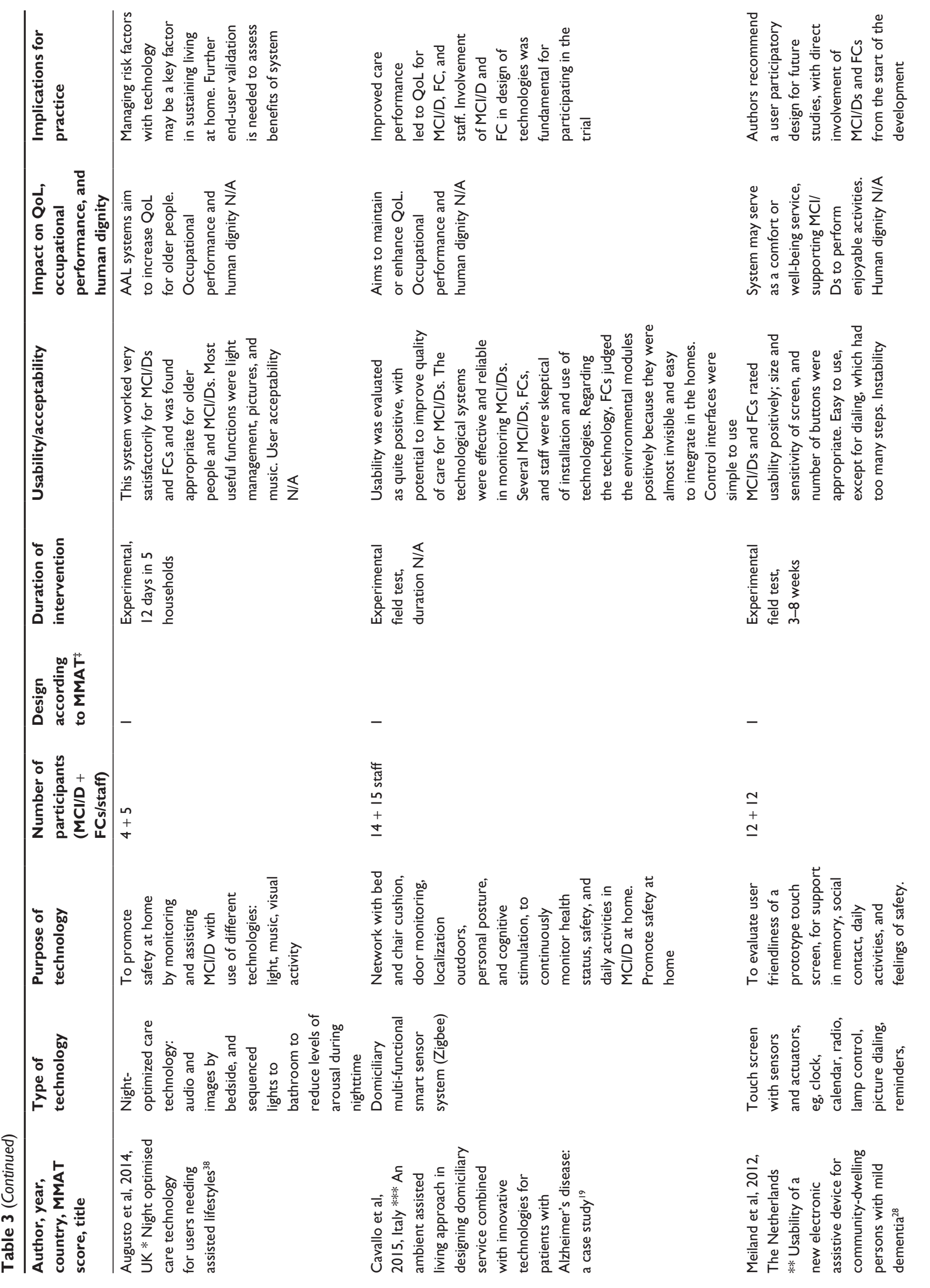




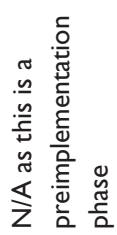

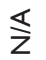
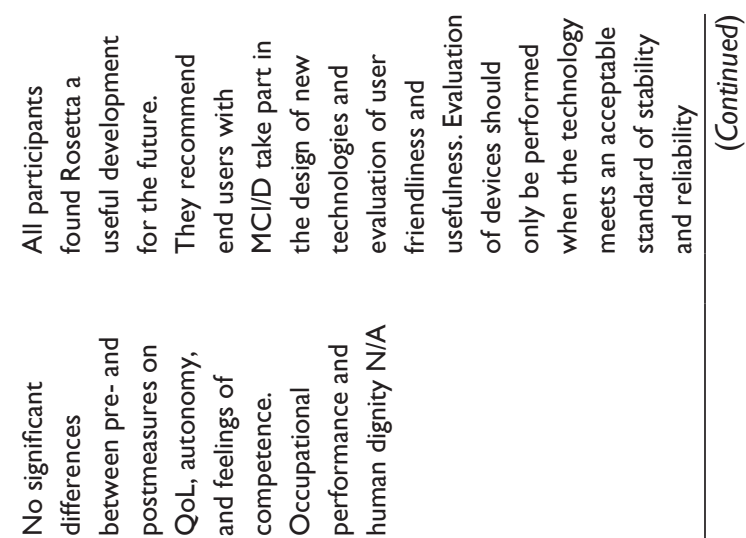

产㐫

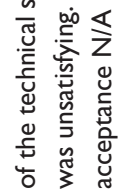

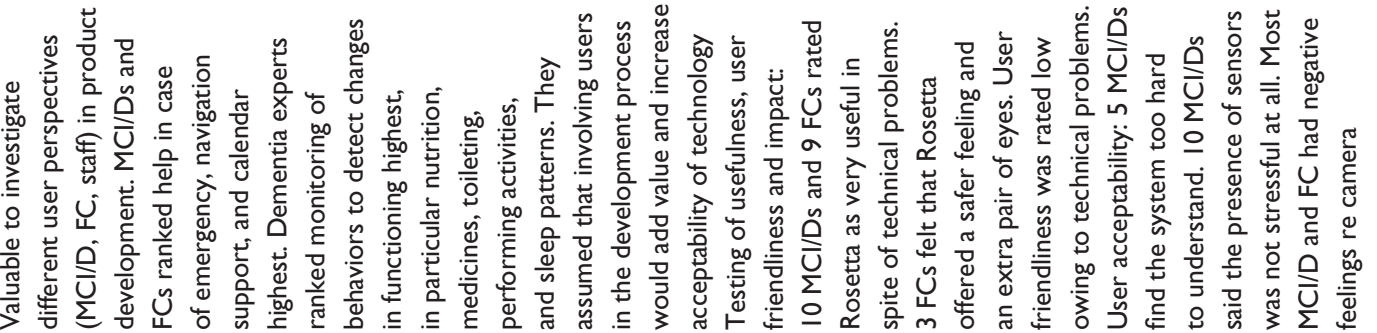

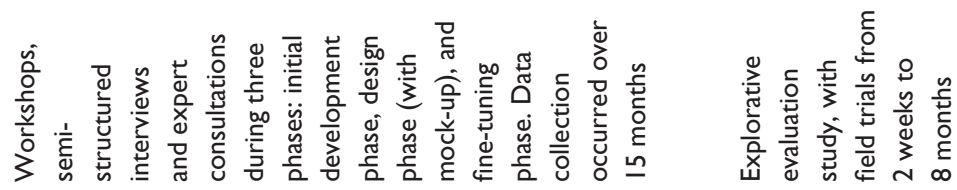

$\stackrel{2}{m}$
+
\pm
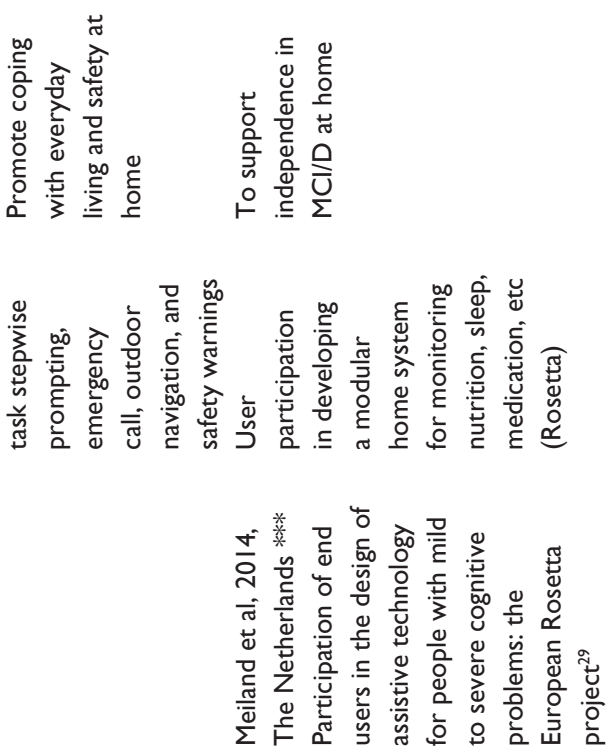

는
+
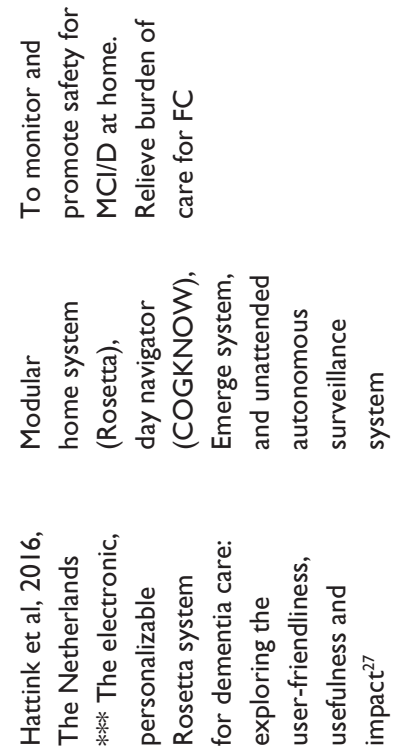


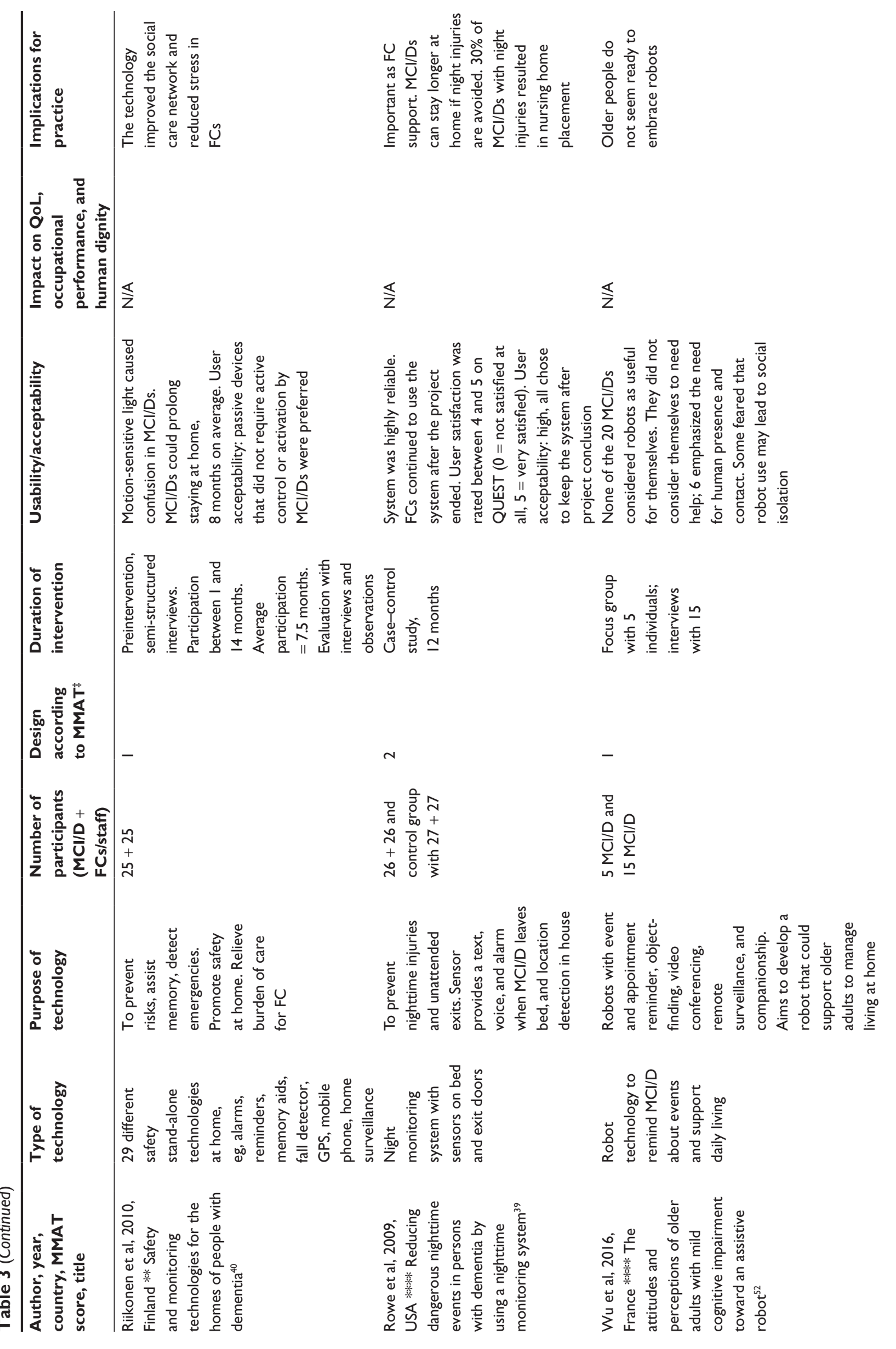



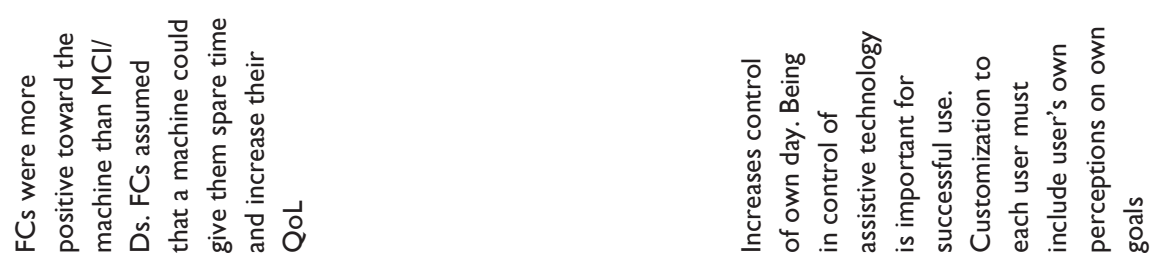

$\stackrel{\varangle}{z}$

$\overleftarrow{z}$

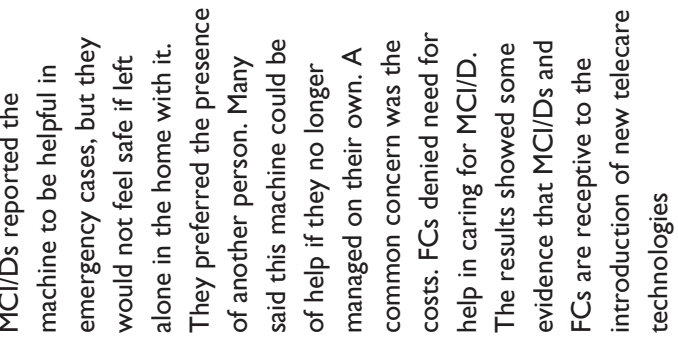
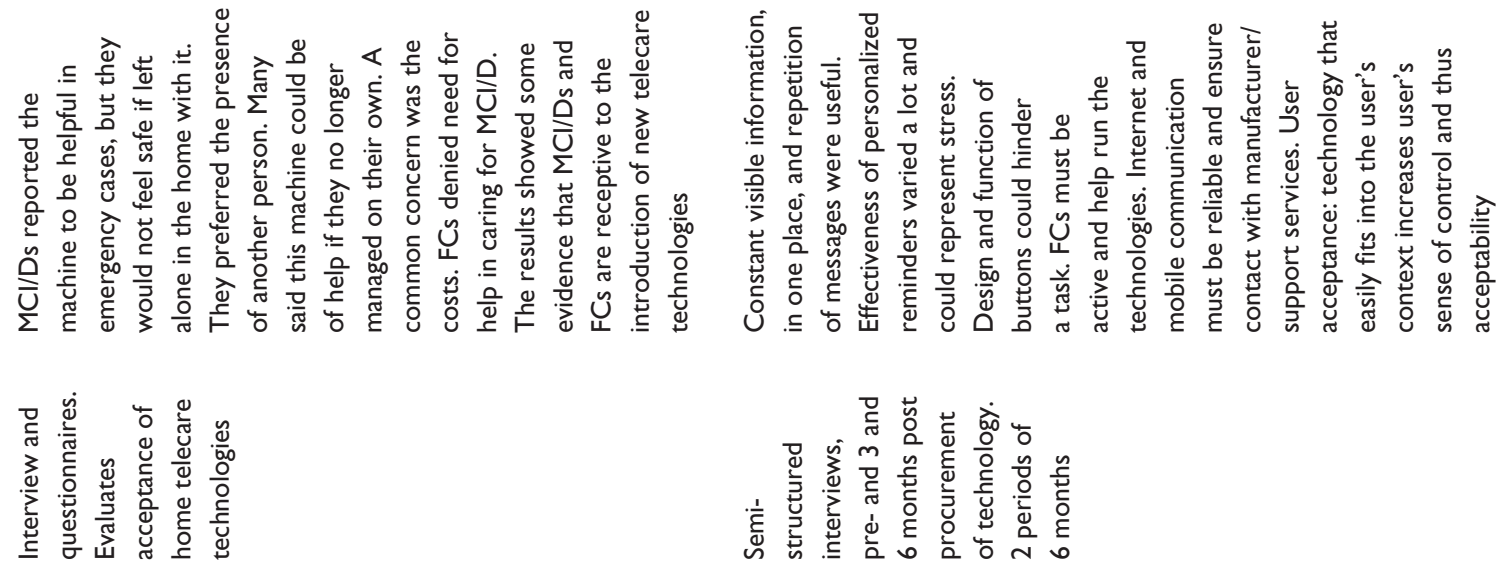

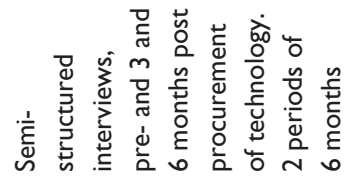

을
+
ก

\pm
+
\pm
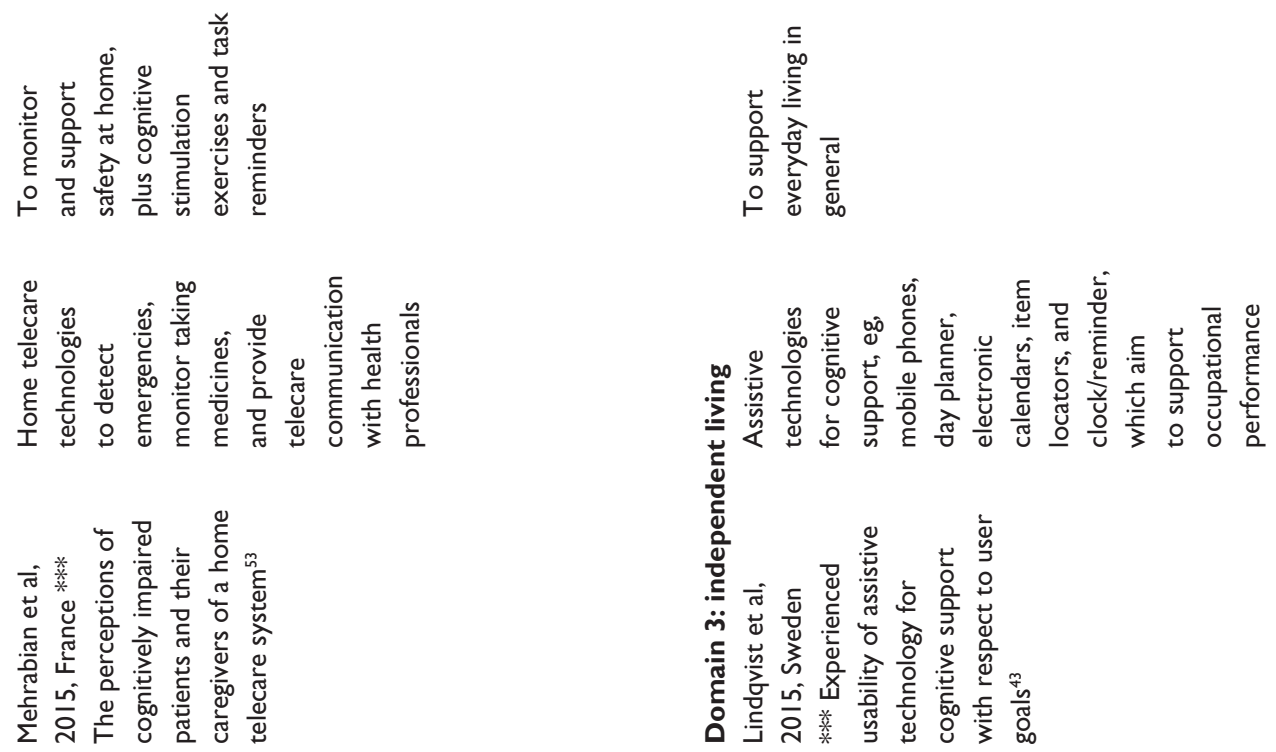


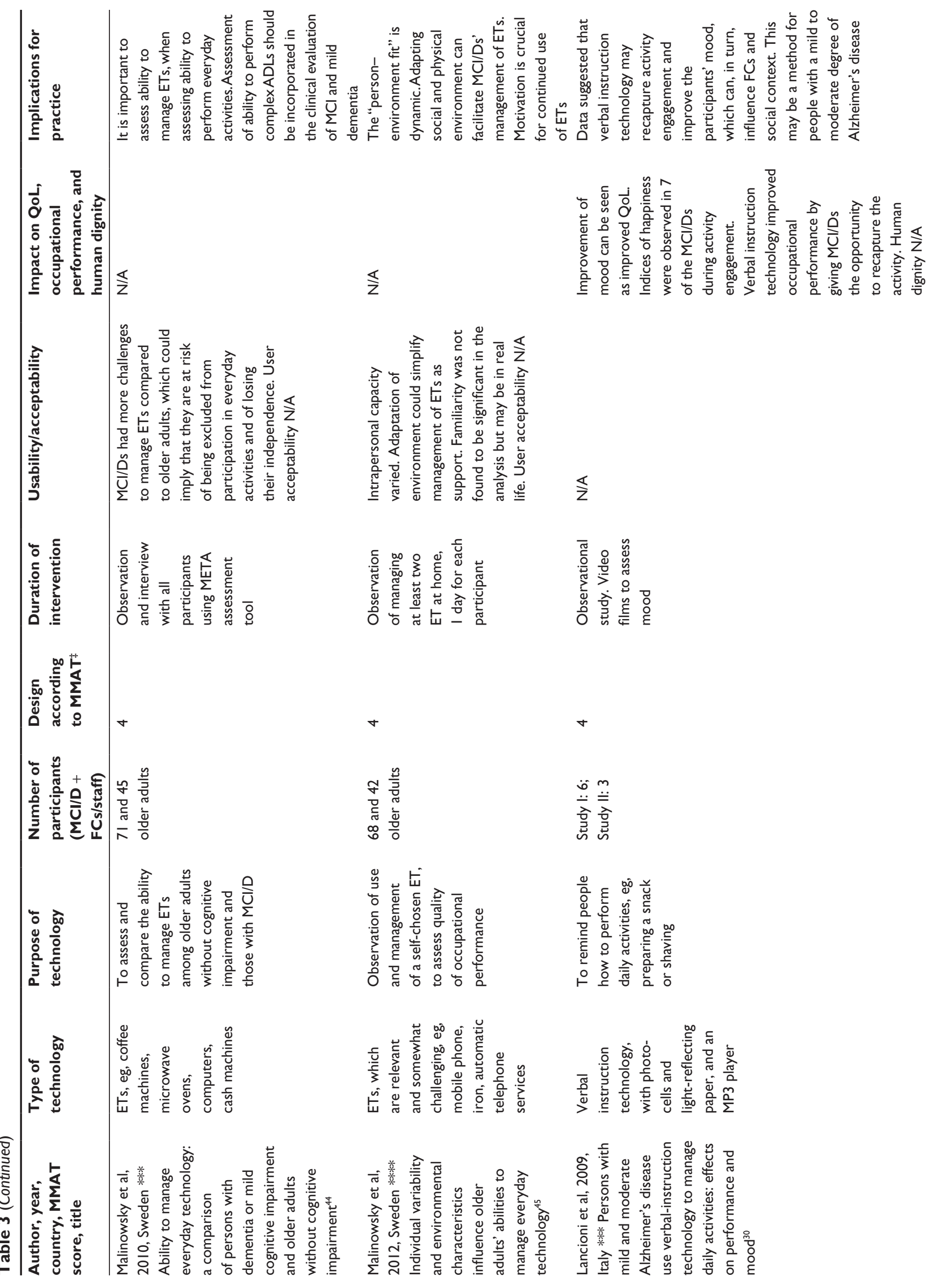



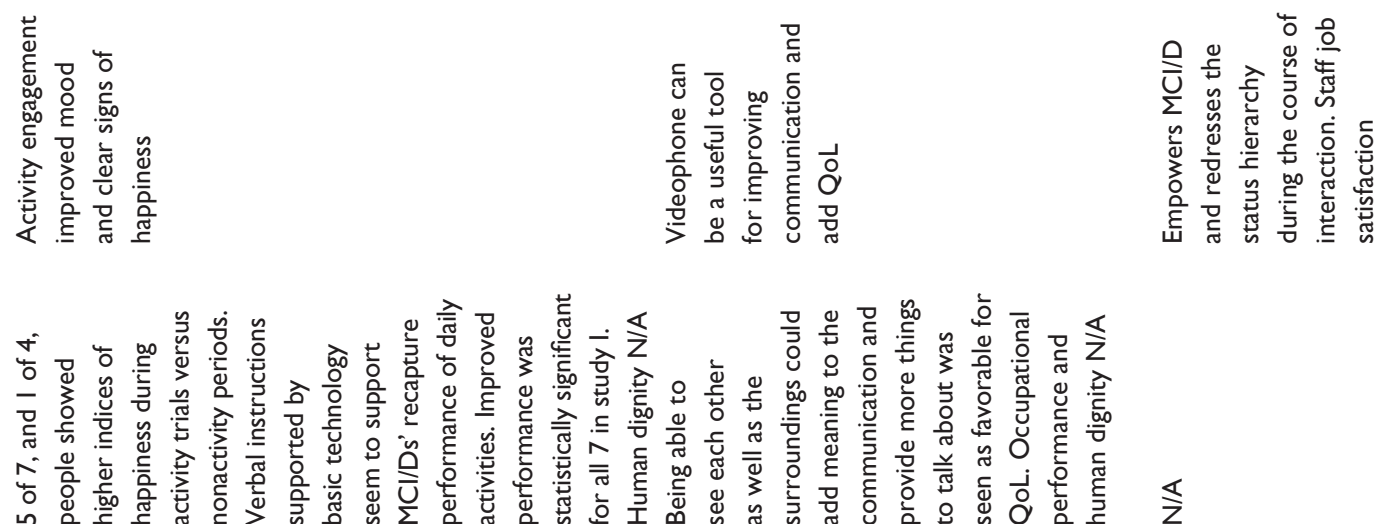

\section{$\$$}

$\stackrel{s}{z}$

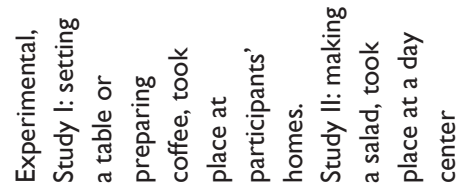

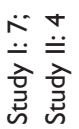

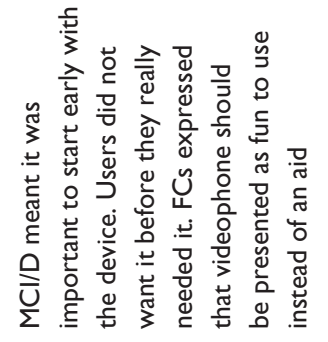

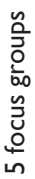

$\stackrel{\infty}{+}$

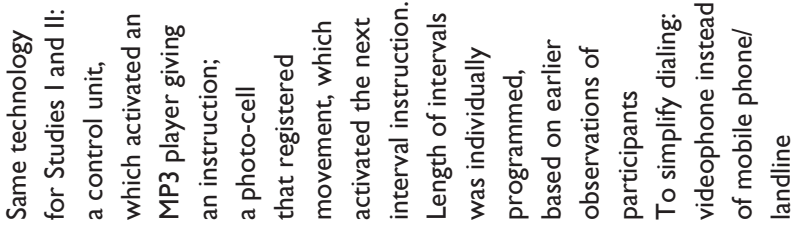

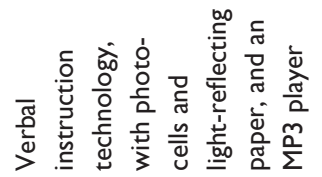

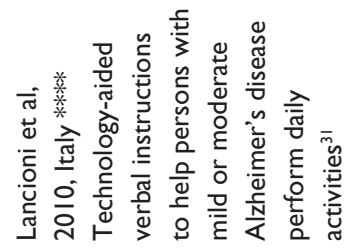

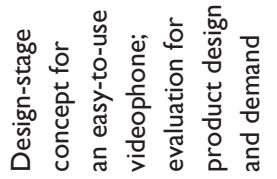

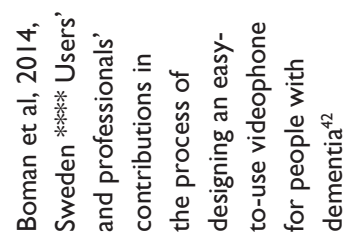

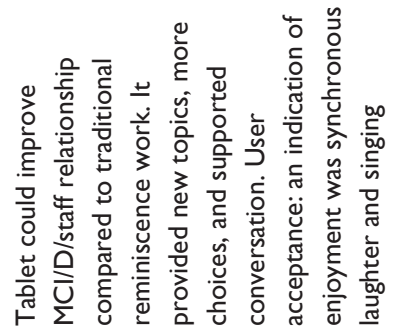

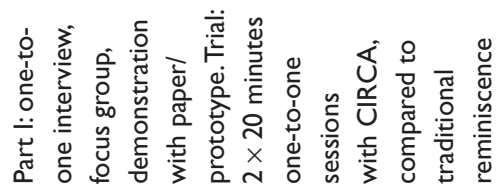

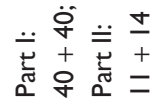

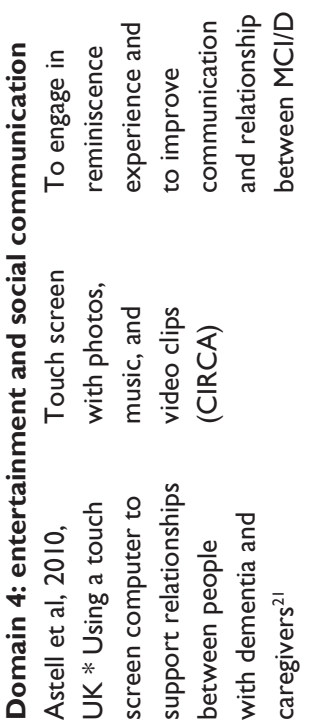




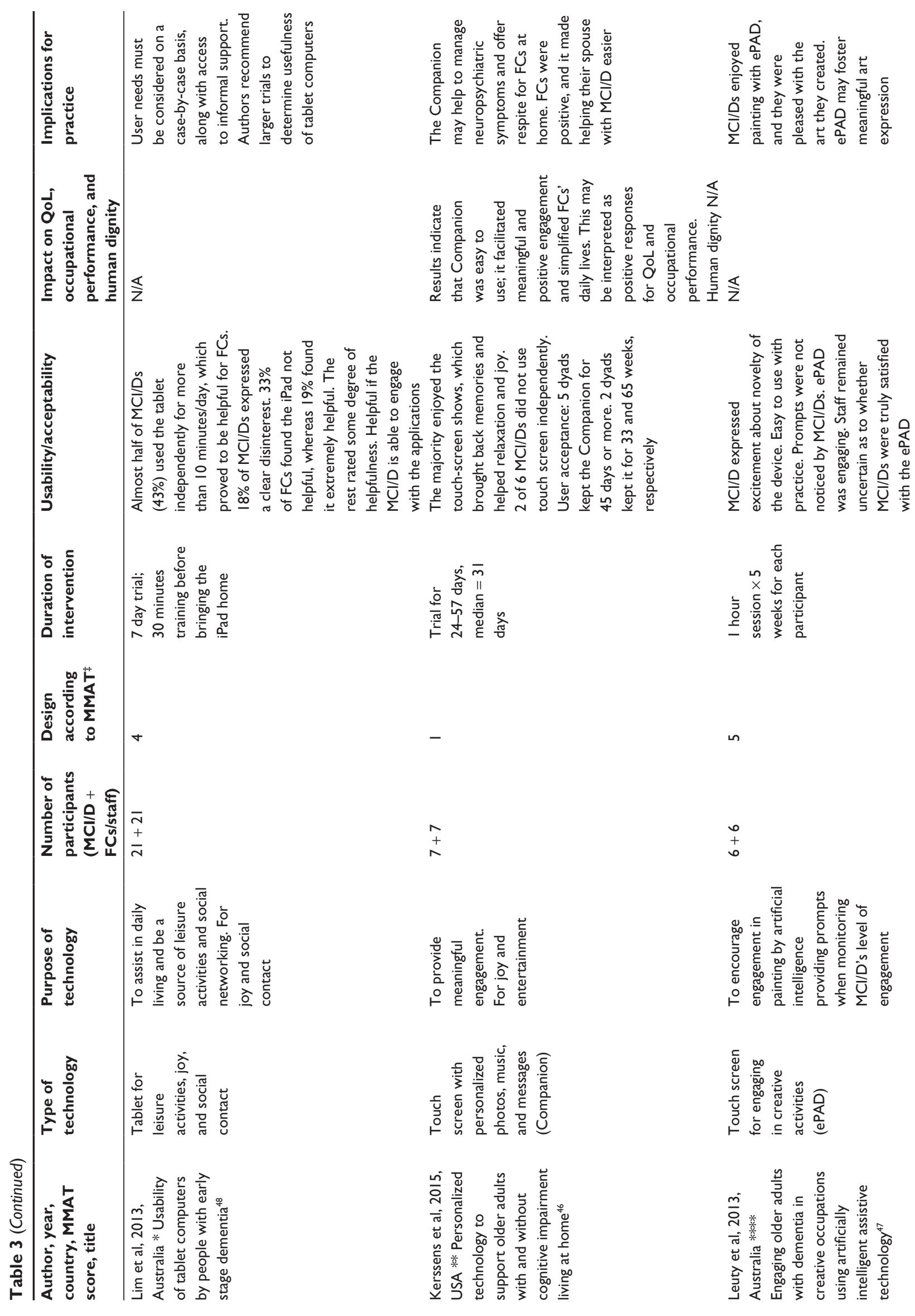



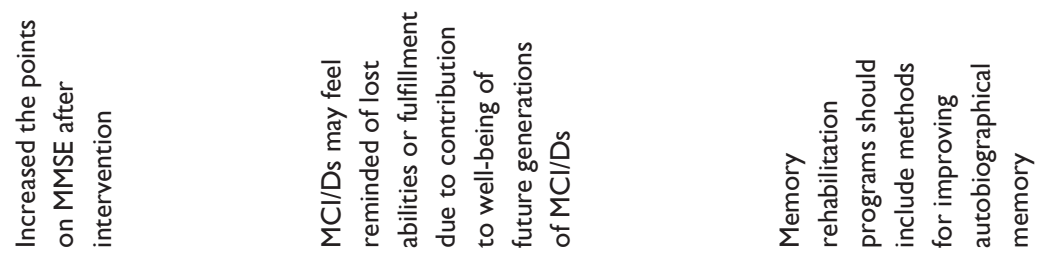

$\frac{5}{z}$

$\frac{\pi}{z}$
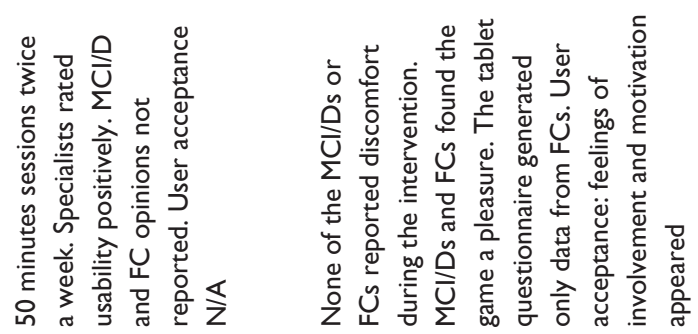

$\stackrel{n}{+}$
$\stackrel{+}{0}$
$\stackrel{+}{\sigma}$

$\stackrel{n}{+}$
$\stackrel{5}{0}$
$\stackrel{\sigma}{\sigma}$

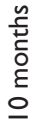

$\begin{array}{ll}- & \simeq \\ - & \simeq\end{array}$

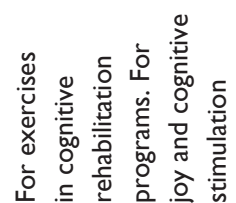

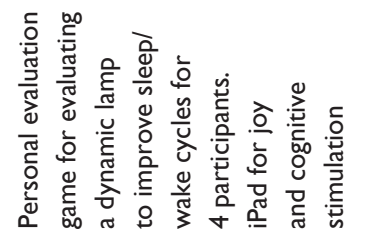

$\mp$

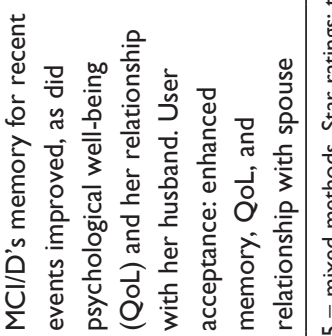
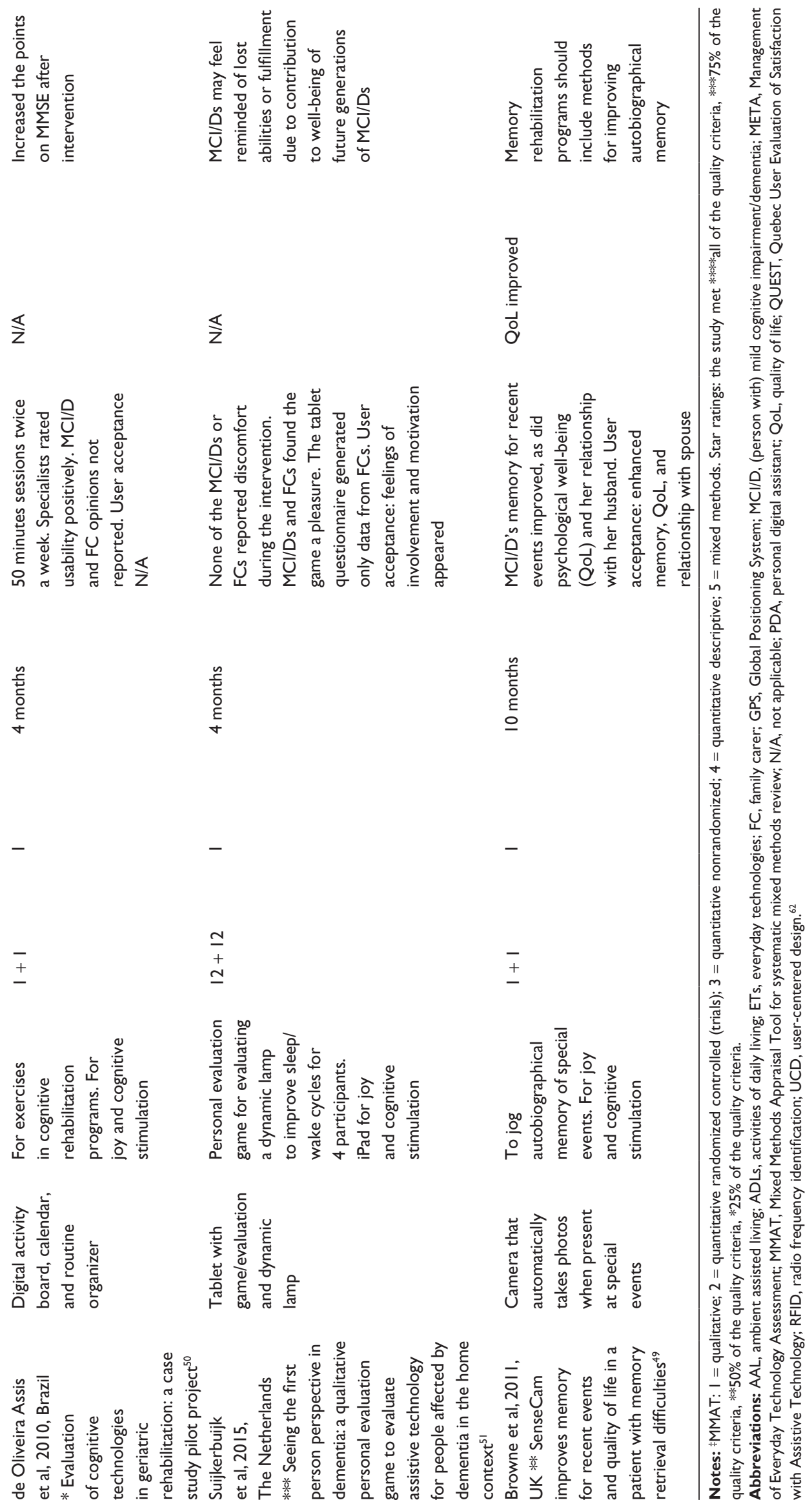

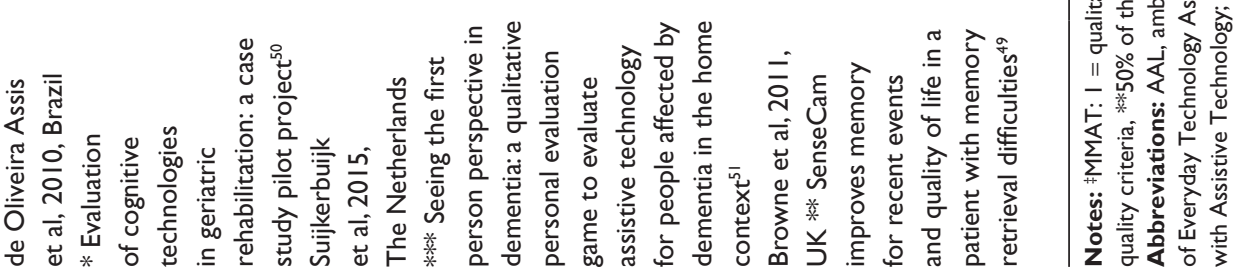




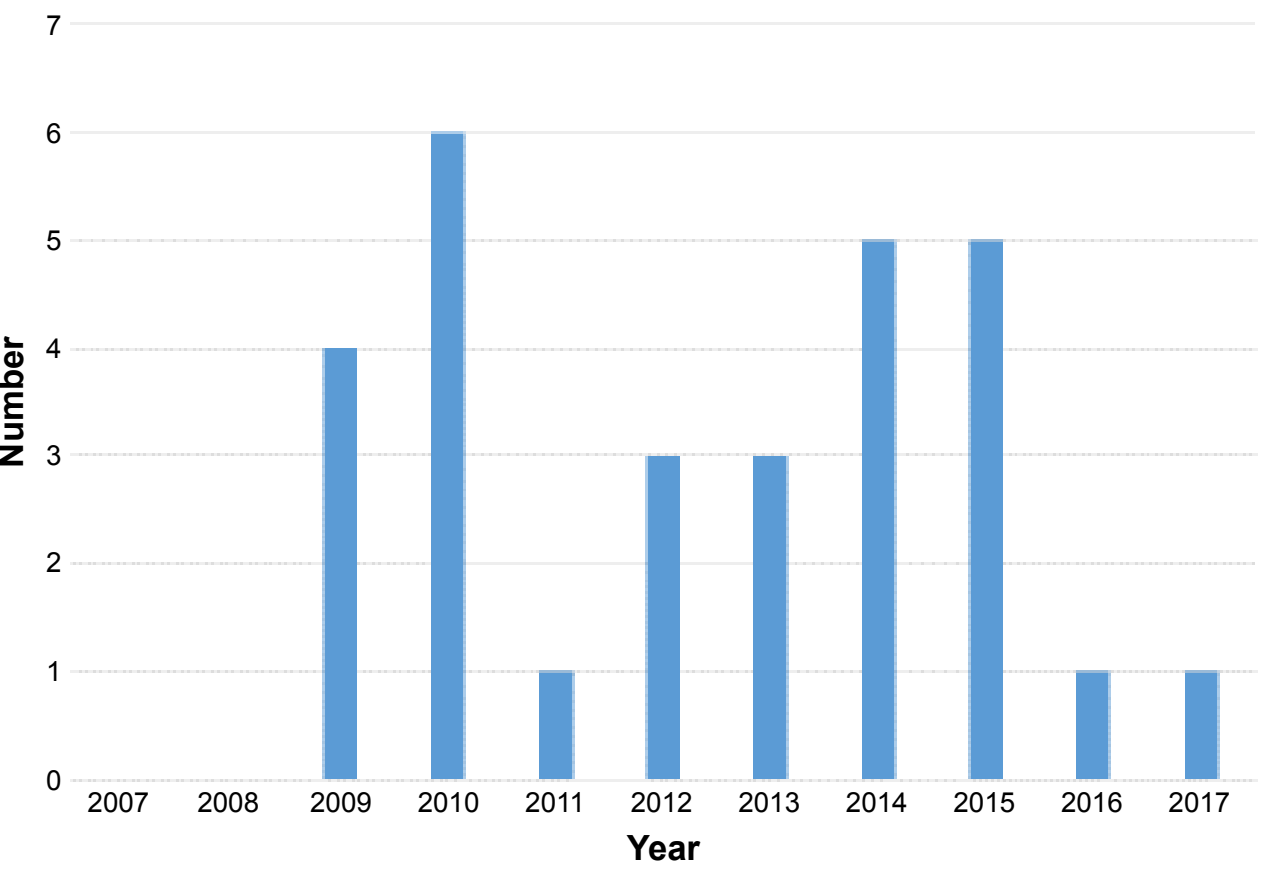

Figure 2 Number of papers per year.

\section{Characteristics of included studies}

The number of papers published per year varied throughout the past decade and had a peak in 2010 with seven published papers (Figure 2).

The 29 included papers consisted of 17 qualitative studies, one quantitative randomized controlled trial, two quantitative nonrandomized studies, seven quantitative descriptive studies, and two mixed methods studies. The studies mostly took place in Western countries (Figure 3), and three papers were connected to the COGKNOW and Rosetta projects. ${ }^{27-29}$ Another author had published more papers on the same technology. ${ }^{30,31}$
The reviewed papers explored several different technologies in conjunction with persons with $\mathrm{MCI} / \mathrm{D}$ and their FCs. Most of the studies took place in Europe. However, Taiwan, Brazil, the USA, and Canada were also represented, and all these studies contributed to greater knowledge in the field.

\section{Study participants}

The participants in the 29 included papers were older people with MCI or dementia, above 65 years of age. Different terminologies described these participants: older adults with cognitive impairment, Alzheimer's patients, persons

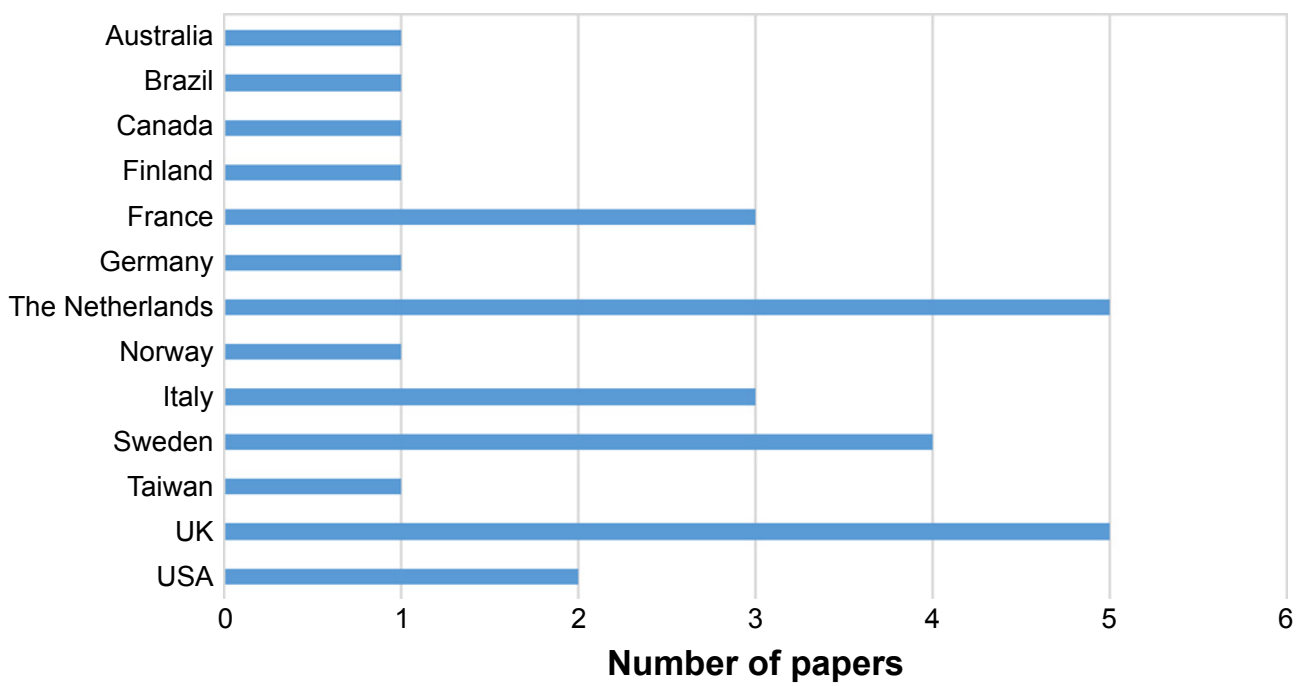

Figure 3 Overview of papers per country 2007-2017; for papers written in collaboration with authors from other countries, only the first author's country is counted. 
with dementia, users, care recipients, etc. In this review, all primary participants in the target group, people with cognitive impairment due to dementia or MCI, are called “people/persons with MCI/D." In total, 665 people with dementia and 83 people with MCI had been involved in the 29 technology studies.

The FCs were named informal carer, spouse, relative, significant other, etc. In this paper, we use the expression FC for all. In total, 248 FCs took part in the 29 studies.

Health workers were named formal carer, nurse, therapist, home-care worker, etc. We chose the term "staff" for all professional health personnel. In total, 55 staff members and 23 others (older adults, dementia experts, volunteers) had taken part in the 29 studies.

\section{What types of technologies have been explored with older people with MCI/D?}

The first research question was to establish an overview of the types of technologies that had been evaluated with older adults with $\mathrm{MCI} / \mathrm{D}$ and their FCs in everyday life. After listing the technologies studied, we grouped them into four domains according to aims and purposes: 1) safe walking indoors and outdoors; 2) safe living; 3) independent living; and 4) entertainment and social communication.

Columns two and three of Table 3 provide an overview of the types of technology and their purposes, and thus answer the first research question.

Domain 1 presents six papers on technology either for locating persons ${ }^{32-34}$ or for supporting navigation, ${ }^{35,36}$ or on how to involve users in the product design of devices for location and navigation. ${ }^{37}$ Domain 2 presents 10 papers on technologies for enhancing safe living, with five studies focused on monitoring systems, ${ }^{19,29,38-40}$ including two papers particularly describing technology for nighttime security. ${ }^{38,39}$ Further, one paper investigated "stand-alone" technologies to enhance safe living, ${ }^{40}$ and one study investigated user requirements prior to the development of a safety wristband. ${ }^{41}$

Domain 3 presents six studies that explored possibly improved occupational performance with the help of technology. ${ }^{30,31,42-45}$

Domain 4 presents seven studies on technologies for entertainment and leisure. Four papers explored the use of touch-screen tablets (iPads). ${ }^{21,46-48}$ One study explored using a camera to document personal events with the intention of reminding the person of (jogging the memory for) recent events, ${ }^{49}$ and one study used a digital board with a touch screen for both cognitive stimulation and joy. ${ }^{50}$
In general, some technologies were multifunctional and could therefore belong to more than one domain. Seven studies described user participation with MCI/D and their FC to identify user requirements, as recommendations for development of design of products (see "How users were involved in technology development," later in this section). Only one study compared the user friendliness of two different strategies for indoor navigation for people with MCI/D; namely, a radio frequency identification navigation device (a device communicating with radio frequency signals) compared with an aerial map. ${ }^{36}$ Suijkerbuijk et al (2015) asked users with $\mathrm{MCI} / \mathrm{D}$ to evaluate their use of a dynamic lamp, which aimed to improve sleep/wake rhythms, by answering questions playing a personal evaluation game on an iPad ("Angenaam") (eight couples) or answering a questionnaire using a tablet (four couples). ${ }^{51}$

\section{Current knowledge about the usability and acceptability of the explored technologies}

Our second research question was about the usability and acceptability of the technologies with regard to occupational performance, QoL, and human dignity for independent living. Column seven in Table 3 presents the knowledge on usability and acceptability in the reviewed studies, while column eight presents findings related to QoL, occupational performance, and human dignity.

\section{Usability and acceptability in the reviewed studies}

Many of the studies explicitly aimed to evaluate the usability of the technologies that were explored. $19,28,38,40,43,47,49,51$ Cavallo et al (2015) found that perceived usability could improve QoL for people with MCI/D and their FCs. ${ }^{19} \mathrm{Cav}-$ allo et al (2015) ${ }^{19}$ Leuty et al (2013), ${ }^{47}$ and Lindqvist et al $(2015)^{43}$ used the same definition as this review regarding usability. Meiland et al (2012, p. 584) explained usability in terms of "user friendliness" (gratifying, easy to manage), "usefulness" (meeting the needs and desires of people with dementia), and "effectiveness" in promoting autonomy, coping, and QoL. ${ }^{28}$ Lindqvist (2015, p. 138) operationalized the concept of usability to include three factors: the user's desired goals, the hindering task according to the user, and the chosen assistive technology. ${ }^{43}$ Some researchers used the term "user friendliness" instead of usability. ${ }^{28,42}$ Boman et al (2014, p. 170) stated that acceptance of technology has been associated with "the ability to maintain a certain desired self-image of being competent." ${ }^{" 42}$ 
None of the studies explicitly evaluated the acceptability of technologies. Some studies reported degrees of acceptance in people with MCI/D and FCs; for example, finding a device ugly could be interpreted as being not accepted, ${ }^{32}$ while experiences of fewer worries for the person with MCI/D or spare time for the $\mathrm{FC}^{33}$ could mean that the device is accepted.

\section{Usability and acceptability of technology that aims to provide safe walking}

Safe walking outdoors refer to the opportunity for people with $\mathrm{MCI} / \mathrm{D}$ to go for walks alone. Safe walking involves many aspects: strategies for wayfinding, the ability to return to the starting point, physical strength/endurance, balance, judgment of one's own physical capacity, vision, footwear, the surface of the outdoor area, and surrounding characteristics, such as woods, beaches, parks, or cities with heavy traffic, etc. Three papers included the GPS as the subject for technology evaluation. ${ }^{32-34}$ The studies from 2009 and 2011 included a GPS localization device, whereas the study from 2017 included a wearable arm-wrist mobile safety alarm with GPS and two-way communication, which can be used both indoors and outdoors, 24 hours a day. GPS is a technology mainly used for the localization of a person. One dyad case study found that the user agreed to carry the GPS only to reassure his wife, and he perceived the GPS as a limitation rather than an instrument of freedom, as his wife did. The couple stressed that the device should not be stigmatizing but rather unnoticeable and support autonomy. ${ }^{32} \mathrm{FC}$ users of GPS technology expressed fewer worries and reported that the technology was easy to use..$^{33}$ Røhne et al (2017) found that people with $\mathrm{MCI} / \mathrm{D}$ who had a mobile safety alarm were able to stay longer at home. ${ }^{34}$ Two other studies explored navigation technologies for indoor wayfinding. ${ }^{35,36}$ Chang et al (2010) tested a prototype of near-field radio frequency identification technology, having six people with $\mathrm{MCI} / \mathrm{D}$ find their way from A to B in a hospital setting,,$^{35}$ and Lanza et al (2014) compared the use of mobile navigation technology with photographs to ordinary aerial maps for autonomous outdoor wayfinding within a large hospital campus. ${ }^{36}$ Both studies found that the participants with MCI/D managed wayfinding in approximately half of the attempts. Therefore, the evaluated technologies seemed promising, given that repeated training sessions are available.

\section{Usability and acceptability of technology for safe living}

Five studies explored integrated monitoring systems, also called AAL, that aim to support independent living and detect risks/events in the home to send alerts in case of accidents. ${ }^{19,27-29,38,39}$ The purposes of these technologies varied somewhat, including to "support MCI/D at home," ${ }^{, 27}$ to create "safe environments and prevent injuries and avoid unattended exits at night," 39 and to "monitor health status, safety, and activities of daily living". ${ }^{19}$ AAL could also imply a strategy to decrease the burden of care for $\mathrm{FCs}^{40}$ and to postpone the need for transition to a nursing home. ${ }^{39}$

The AAL systems could also offer multimodal assistive services, with cognitive stimulation ${ }^{38}$ providing reminders to the person with dementia about events or tasks to carry out, and facilitating communication with family and friends. ${ }^{28}$ The AAL systems normally required internet-based computers. ${ }^{28}$ None of the papers presented perceptions of these AAL technologies from the perspective of those with $\mathrm{MCI} / \mathrm{D}$.

One paper ${ }^{40}$ presented user experiences with different "stand-alone" technologies that are not a part of a system but that still aim to contribute to safety at home by preventing risks, detecting emergencies, and assisting the memory of persons with MCI/D. Riikonen et al (2010) found that such technologies contributed to decreased stress in FCs. People with $\mathrm{MCI} / \mathrm{D}$ seemed to accept best passive devices that did not require active control or activation. ${ }^{40}$

\section{Usability and acceptability of technology for independent living}

Some technologies aimed to promote independence and autonomy by compensating for lost cognitive skills, for example, by providing reminders via a sound, a light, and/or a written or spoken message. Because cognitive impairments affect occupational performance, compensatory technology can be useful for some. Lancioni et al (2010) tested verbal instruction technologies to remind persons with $\mathrm{MCI} / \mathrm{D}$ about the steps in a given task, and this strategy seemed to help them recapture the performance. ${ }^{31}$ One study presented occupational performances of self-chosen, everyday technologies, ${ }^{45}$ and found that both intrapersonal capacities and environmental characteristics influenced the performance of handling the technology.

\section{Usability and acceptability of technology for entertainment and social communication}

Six studies tested computer tablets and iPads with people with MCI/D. ${ }^{21,46-48,50,51}$ The purposes were mainly to provide meaningful engagement ${ }^{21}$ and cognitive stimulation from photos, music, and games. ${ }^{46,48,50}$ De Oliveira Assis et al (2010) 
found that 50 minutes of cognitive stimulation programs twice a week positively influenced cognitive functioning, as demonstrated with pre-post measures on the Mini-Mental State Examination. ${ }^{50}$ Another study used tablet computers in art activities, which was appreciated by participants with MCI/D. They expressed excitement about the novelty of the device and satisfaction with the art they made. ${ }^{47}$ The therapists, however, remained uncertain as to whether the $\mathrm{MCI} / \mathrm{D}$ participants were truly satisfied with the tablet computers. ${ }^{47}$

Astell et al (2010) evaluated tablets as social communication and reminiscence devices between staff and people with MCI/D. They compared the use of tablets to traditional reminiscence work, and found that the tablets increased the interaction between staff and residents, empowering people with $\mathrm{MCI} / \mathrm{D}$ and redressing the status hierarchy during the course of the interaction, as well as leading to increased job satisfaction in staff members. ${ }^{21}$

Tablets were also explored regarding entertainment and joy. Kerssens et al (2015) found that the majority of seven persons with $\mathrm{MCI} / \mathrm{D}$ enjoyed the touch-screen shows, which brought back memories and helped with relaxation and joy. However, two of the six persons with $\mathrm{MCI} / \mathrm{D}$ did not use the touch screen independently. ${ }^{46}$ Lim et al (2013) found in their study of 21 people with MCI/D that almost $43 \%$ used the tablet independently for more than 10 minutes/day, which proved to be helpful for FCs. However, 18\% of the people with $\mathrm{MCI} / \mathrm{D}$ expressed a clear disinterest. The study concluded that user needs must be considered on a case-bycase basis, along with access to informal support. ${ }^{48}$

\section{How users were involved in technology development}

This subsection answers the third research question: How are users involved in the reviewed technology studies?

One major finding, represented in all 29 papers, emphasizes user involvement in preimplementation technology design and development and feasibility testing. Several studies highlighted the need to identify and confirm user needs in older adults with MCI/D in order to develop useful technologies, as earlier studies had mainly asked proxy persons these questions. Potential users of the technology include persons with $\mathrm{MCI} / \mathrm{D}$, their FCs, and staff, and they took all part in the studies we reviewed (see column four in Table 3). ${ }^{28,29,37,38,41,42,52}$ Some studies showed prototypes or mock-ups of the technology in question, in order to facilitate users' responses on perceptions and opinions. ${ }^{29,41}$ Involving people with dementia in the process of participatory design is feasible. This could lead to the development of devices that are more acceptable and relevant to their needs. ${ }^{41}$ According to Cavallo et al (2015), the involvement of persons with $\mathrm{MCI} / \mathrm{D}$ and FCs in the design of technologies was fundamental for participation in a trial. ${ }^{19}$ Meiland et al $(2014)^{29}$ and Hattink et al (2016) $)^{27}$ explicitly recommended user participation in the design of new technologies and evaluation of their user friendliness and usefulness.

The study designs for user involvement varied. The most frequent design was the focus group. Five studies carried out focus groups for MCI/D and four for FCs. ${ }^{29,37,38,42,52}$ Two studies used workshops as the method for user engagement, ${ }^{29,41}$ and six studies used observation as method. ${ }^{28,40,43-45,53}$ Most studies used more than one method for data collection (see column five, Table 3).

Nine studies were experimental trials, which often started with a workshop or focus group with $\mathrm{MCI} / \mathrm{D}$ participants and FCs/staff to identify user needs and requirements. ${ }^{19,29,38}$ Thereafter, the same participants were invited to give their opinions on a mock-up or prototype device installed at home, in order to evaluate usability and acceptance. The primary aim was to hear the voice of the $\mathrm{MCI} / \mathrm{D}$ participant and to learn about the usability of the device. Only three studies were randomized controlled trials, with a pre-posttest design and control group. ${ }^{29,36,39}$

Some studies underlined the necessity of tailoring the technology to the user's needs and preferences. ${ }^{33,43,48}$ Pot et al (2012) stated that the specific problem for the person with $\mathrm{MCI} / \mathrm{D}$ and FC must be defined, in order to identify the most appropriate solution. ${ }^{33}$ During the user-needs assessment, it is thus important to assess the user's ability to manage the everyday technology that they already possess and are familiar with before any new technology is introduced. ${ }^{45}$ According to Malinowsky et al (2010), intrapersonal skills and environmental characteristics influence performance and management of technologies, but at the same time, the "person-environment fit" is dynamic, ie, it will change over time. ${ }^{44}$ Adaptation of the social and physical environment can facilitate the management of everyday technologies by people with MCI/D. ${ }^{44}$ Further, each user's customization to the technology always depends upon the self-perception of his or her own goals. ${ }^{43}$ If the technology was evaluated as positive, it proved successful in improving the social (care) network and reduced stress in FCs. ${ }^{40}$

\section{Discussion}

This review aimed to obtain an overview of the types of technologies being explored with persons with $\mathrm{MCI} / \mathrm{D}$, identifying 
the usability and acceptability of such technologies with regard to occupational performance, QoL, and human dignity, as well as to learn how user involvement of those with $\mathrm{MCI} / \mathrm{D}$ and FCs was achieved in these studies.

\section{Types of technologies}

The reviewed studies showed a wide range of technologies, such as GPS, monitoring systems, tablets, touch-screen computers with calendar, clock and task reminders, verbal instruction technology, and robot technology, which we categorized into four domains related to the purposes of everyday living: safe walking, safe living, independent living, and entertainment and social communication. However, the technologies within the domains may overlap. For example, a stove timer with the purpose of safety at home can be a "stand-alone" device or a part of AAL technologies, with the potential to send an emergency alarm. Likewise, a digital calendar for supporting a person's memory may be a separate device, as well as part of a digital structure enhancing safety at home. Sometimes, technologies may benefit others than the person with dementia. Gibson et al (2016, p. 7) conducted a scoping review and found 171 types of assistive technologies, which they divided across three areas: "'assistive technology used 'by', 'with,' and 'on' people with dementia." ${ }^{4}$ Another divide can be between "active" and "passive" technologies, ${ }^{63}$ depending on the person with MCI/D's role as a technology user. Lindqvist et al (2015) stated that the person with MCI/D's perception of the extent to which their own goals have been achieved must be included to assess the usability of a product or solution. $^{43}$

\section{Usability and acceptability}

Technology that is simple to use and enables a person with reduced cognitive capacity to cope independently with daily tasks and obligations is classified as being usable and acceptable. The usability of technology was defined as user friendliness, usefulness, and effectiveness, ${ }^{28}$ and by the extent to which a product can help a user to achieve a specific goal. User-friendly technologies are thus a means to enable older adults and people with reduced capacities to engage in activities and participate in society, equal to other citizens. McCreadie and Tinker (2005) found that a technical device must address a person's "felt need" in order to be perceived as useful. ${ }^{55}$ This is in line with Peek et al (2014, p. 242), who found that a perceived personal need for technology was the most frequent factor mentioned for technology use and acceptance. ${ }^{56}$
Several authors referred to the International Organization for Standardization's definition of usability..$^{19,43,47}$ However, it may be interesting to discuss usability related to utility and identity. Ravneberg and Söderström (2017) stated that usability is used synonymously with user friendliness and easy to use/learn, while utility is the functionality of the technology, and identity is connected to a user's opinion of whether the device/aid matches the user's personal character and reflects the person's identity. ${ }^{15}$ These aspects may be difficult to distinguish and will influence the acceptability of a device. The degree to which the technology was accepted depended upon the end users' experiences of reliability and stability of the technical performance of the device. ${ }^{28}$ Acceptability also considers whether the device matches the user's identity. ${ }^{15}$ This may explain why users may hesitate to wear a device (eg, GPS) in their belt or pocket. The device may make the user feel stigmatized and result in rejection of the device. Some older adults will perceive a technology as being more relevant for other elderly people with more extensive functional impairments ${ }^{56}$ and be less motivated to use it themselves. One major consideration is the ability and motivation of the person with $\mathrm{MCI} / \mathrm{D}$ to accept and incorporate such technologies in their everyday living. ${ }^{24}$ A Swedish study that found that older adults with MCI strived to downsize their approaches toward everyday activities, owing to changing abilities. They achieved this by using familiar technologies in a new way, by replacing old technology with something simpler. Sometimes they chose to stop using technology, although they needed it, or they had a desire to update their technology use. ${ }^{57}$ However, downsizing use of technologies will become a challenge when the health services seek to implement new technologies. Older adults may be reluctant to use new technology that they not yet are familiar with. ${ }^{58}$

However, one finding was that usability of technology often was rated low at the beginning of the project, ${ }^{19}$ which may be associated with late or nonadopters of technologies, or with skepticism toward new technologies. Also, it could be that FCs were unaware of the potential of the technologies and feared that they would not be appropriate for the person with MCI/D. Peek et al (2016, p. 4) revealed that older adults stated that such technologies were not necessarily intended for them, but rather "for others, less healthy older people." 58

Engaging older adults in a preimplementation study thus risks obtaining a "prototypical result," according to Peek et al (2014). ${ }^{56}$ Posttrial evaluation of usability and acceptability was more positive as users had experienced the technologies' potential to improve the quality of care. ${ }^{19}$ 
A clinical trial allowing end users to try the technology at home, in real-life situations, seemed to be an eye-opener by giving older adults the opportunity to realize how technology may, or may not, be of benefit. Therefore, clinical trials with end users are needed to evaluate the usability and acceptability of technologies.

Surprisingly, less than half of the 22 reviewed studies on technology trials reported the perceptions of the participants with MCI/D on the usability and acceptability of the explored technologies. The proxy opinions of FCs and staff were mainly reported. This finding leads us to ask why the opinions of the participants with $\mathrm{MCI} / \mathrm{D}$ were so scarcely reported.

\section{User involvement in the studies}

User involvement was included in all the reviewed studies, which involved both persons with $\mathrm{MCI} / \mathrm{D}$ and their FCs or staff. User involvement requires a bottom-up approach: that developers and researchers assess persons' experiences with technology tried at home and consider those opinions when furthering development work. The evaluation of a product or solution with potential end users is a way of ensuring that the device works sufficiently for the target group. Some of the studies highlighted that the technology must be tailored to the user in order to be useful and usable. ${ }^{19,43,45,52}$ The study by Robinson et al (2009) contained a three-stage user-centered design (UCD) process involving persons with $\mathrm{MCI} / \mathrm{D}$ and $\mathrm{FCs}^{41}$ (UCD was introduced by Rubin in 1994, ${ }^{59}$ as a method to explore user needs and requirements and put the user at the center of the design process.). Robinson et al (2009) concluded that user engagement resulted in products that were more acceptable and relevant to the users' needs. ${ }^{41}$ Augusto et al (2014) implemented technology in accordance with UCD principles, to monitor the sleep/wake patterns in five households dealing with persons with dementia and their FCs. Thereafter, they developed an appropriate technological solution together. This exploration informed improved design of user interfaces. ${ }^{38}$

Even if it is challenging to include people with $\mathrm{MCI} / \mathrm{D}$ in a user-driven development process, it is worthwhile. ${ }^{42}$ Meiland et al (2012) recommend a user participatory design with direct involvement of people with $\mathrm{MCI} / \mathrm{D}$ and $\mathrm{FCs}$, from the beginning of the project and through the whole process. ${ }^{28}$ McCabe and Innes (2013) stated that user engagement in product development provided valuable inputs on how GPS might be designed and used. ${ }^{37}$ They stated that successful devices are those that give consideration to real-life use and concerns from potential users. ${ }^{37}$ In other words, developing user-friendly interfaces, which are found to be usable and acceptable by the end users, requires user involvement.
However, the terms "user" or "end user" might include both persons with $\mathrm{MCI} / \mathrm{D}$ and FCs in the reviewed trials. We found it difficult to distinguish between the opinions of the person with MCI/D and those of the FC or staff on the technologies tried at home. Further research should investigate and report possible discrepancies between these parts.

Finally, the duration of the intervention and the study design influenced results on assessing usability and acceptability, since MCI/D usually progresses over time. Five of the studies lasted for less than 2 months, and eight lasted 6 months or longer. In one study, ${ }^{32}$ the person with dementia and his spouse left the trial after only 1 day. No information or training was provided prior to the trial, which in other studies seemed to be important. For how long should people with $\mathrm{MCI} / \mathrm{D}$ try a product in order to be able to appraise it?

Attitudes toward MCI/D are changing, and nowadays people with $\mathrm{MCI} / \mathrm{D}$ are more aware of their needs and rights. The European Dementia Working Group's slogan, "Nothing about us without us, ${ }^{60}$ underscores their desire for user participation in all service planning and authorizes their expression of own needs and preferences for technological or human support. The findings of this review clearly underscore the value of user involvement in technology development and clinical trials. More research is needed on what happens when technology is introduced to people with MCI/D and their environments, and whether technology will accommodate the needs and wishes stated by people with $\mathrm{MCI} / \mathrm{D}$ and their FCs in a just and ethical way.

\section{Possible biases}

First, our search strategy may contain biases. We had many search words, which were challenging to include in one search. The search stories became long and we had to put extra effort into screening more titles for relevance.

Most of the studies reviewed had small sample sizes, and 10 out of the 29 studies had 10 participants or fewer. This is often criticized as a possible bias because generalization of results is not possible. However, our aim was to explore the width and depth of technology interventions, and small sample sizes nevertheless provided rich data. Further, multiple publications from the same authors/projects ${ }^{24-27,38,39}$ may also skew the impression of the extent of the research.

Another possible bias is the close and regular relation between the participants and the researchers over time, as mentioned by Browne et al (p. 719). ${ }^{49}$ Since many of the experiments had a pre-post design, and follow-up after a period, many participant-researcher relations may have developed beyond a neutral and formal attitude, to a more 
informal and friendly relationship. However, this is difficult to avoid in a participatory action research approach, where the research process relies on collaboration between the researcher and participants. ${ }^{61}$

One bias may be the use of the MMAT matrix for quality assessments of the 29 eligible papers. Five team members rated one-fifth of the papers individually, before comparing the assessment results with another team member. If discrepancies arose, a third team member was involved in the decision. Even though we chose not to exclude any of the papers owing to low quality, the quality assessment provided an overview of the quality of the papers included in our review.

\section{Conclusion}

The research about technologies to support people with $\mathrm{MCI} / \mathrm{D}$ in everyday living seems optimistic, and a wide range of technologies has been evaluated at home with persons with $\mathrm{MCI} / \mathrm{D}$ and their FCs. A major and representative finding was the importance of including those with $\mathrm{MCI} / \mathrm{D}$ and their FCs in research, in order to learn about required design features to enhance usability and acceptability. Few studies reported findings on people with $\mathrm{MCI}$ /D's perceptions of the acceptability and usability of the technologies or on the consequences of technology for QoL and occupational performance. None reported the consequences of technology use relating to human dignity.

\section{Acknowledgments}

We want to acknowledge the Norwegian Research Council, which funded the Assisted Living Project, librarian Bente Schjødt-Osmo, Cappelen Damm, for excellent supervision during the first literature search, and librarian Kristin Røijen, HIOA, for assisting the search of the CINAHL database. Further, we would like to thank the Assisted Living Project group and project leader Ellen-Marie Forsberg, AFI, HIOA (https://assistedlivingweb.wordpress.com/). Finally, we thank Oslo and Akershus University College, HIOA, for financing this Dove Press Open Access publication.

\section{Author contributions}

$\mathrm{TH}$, first author, PhD student, led the review, took part in the literature searches, screened half of the titles, and reviewed all abstracts before a full-text reading of all included papers. She prepared and wrote all versions of this paper for discussion with co-authors, and later completed the paper for submission. All authors contributed toward data analysis, drafting and revising the paper and agree to be accountable for all aspects of the work.
LH, second author, mentor, took part in the literature searches, screened half of the titles, reviewed one-fifth in full text, and carried out the quality assessment according to MMAT. She judiciously contributed to the design of this paper, endorsing and commenting on the work during the entire process, as well as critically revising the article for final approval.

DK, third author, took part in the literature searches, screened half of the titles, reviewed one-fifth in full text, and performed a quality assessment according to MMAT. He contributed to the design of this paper and offered discerning appraisal during the writing process, critiquing and revising this paper for intellectual content.

$\mathrm{K}-\mathrm{AH}$, fourth author, entered the author group somewhat later. She read one-fifth of the titles in full text and assessed the quality of the papers according to MMAT. She read three versions of this paper and contributed with critical appraisal during the writing process.

AL, fifth author, took part in the literature searches, screened half of the titles, reviewed and quality-assessed onefifth of the full-text papers, contributed to the design of the review, and contributed to the writing process. She revised this article for intellectual content and for final approval before it was submitted for publication.

\section{Disclosure}

The authors report no conflicts of interest in this work.

\section{References}

1. von Schomberg R. A vision of responsible research and innovation. In: Owen R, Bessant J, Heintz M, editors. Responsible Innovation: Managing the Responsible Emergence of Science and Innovation in Society. London: John Wiley \& Sons; 2013:51-74.

2. Damodaran L, Olphert W. Foresight Evidence Review: How Are Attitudes and Behaviours to the Ageing Process Changing in Light of New Media and New Technology? How Might These Continue to Evolve by 2025 and 2040? GS/15/17. London: Government Office for Science; 2015:27.

3. Alzheimers.net [database on the Internet]. 2016 Alzheimer's statistics. Available from: alzheimers.net/resources/alzheimers-statistics. Accessed September 13, 2017.

4. Engedal K, Haugen PK. Demens-Fakta og utfordringer. En laerebok [Dementia-Facts and Challenges. A Textbook]. 5th ed. Tønsberg: Forlaget Aldring og helse; 2009.

5. WHO. International Statistical Classification of Diseases and Related Health Problems 10th Revision (ICD-10). F00: Dementia in Alzheimer Disease; 2016. Available from: http://apps.who.int/classifications/icd10/ browse/2016/en\#/F00. Accessed May 15, 2017.

6. Winblad B, Palmer K, Kivipelto M, et al. Mild cognitive impairmentbeyond controversies, towards a consensus: report of the International Working Group on Mild Cognitive Impairment. J Intern Med. 2004;256: 240-246.

7. Petersen RC, Roberts RO, Knopman DS, et al. Mild cognitive impairment: ten years later. Arch Neurol. 2009;66(12):1447-1455. 
8. Hedman A, Nygård L, Almkvist O, Kottorp A. Patterns of functioning in older adults with mild cognitive impairment: a two-year study focusing on everyday technology use. Aging Ment Health. 2013;17(6): 679-688.

9. Lindqvist E, Nygård L, Borell L. Significant junctures on the way towards becoming a user of assistive technology in Alzheimer's disease. Scand J Occup Ther. 2013;20(5):386-396.

10. Nygård L, Starkhammar S. The use of everyday technology by people with dementia living alone: mapping out the difficulties. Aging Ment Health. 2007;11:144-155.

11. Øderud T, Grut L, Aketun S. Samspill_GPSi Oslo. Pilotering av Trygghetspakke 3. Bruk av GPS for lokalisering av personer med demens [Interaction-GPS in Oslo. Piloting Safety Package 3. Using GPS to Locate People with Dementia]. Oslo: SINTEF Teknologi og samfunn, avd. helse, SINTEF IKT; Aug 17, 2015.

12. Ørjasæter N, Kistorp K. Velferdsteknologi i Sentrum (VIS). Innføring av velferdsteknologi i sentrumsbydene i Oslo [Wellfare Technologies in Focus (WIF). Introduction of wellfare technologies in downtown districts of Oslo]; 2016. Available from: https://helsedirektoratet no/Documents/Velferdsteknologi/Velferdsteksnologi\%20i\%20sentrum_delleveranse\%202\%20av\%202.pdf. Accessed May 15, 2017.

13. Townsend EA, Polatajko HJ. Enabling Occupation II: Advancing an Occupational Therapy Vision for Health, Well-Being \& Justice Through Occupation. Ottawa: Canadian Association of Occupational Therapists; 2007.

14. Heggestad A. To Be Taken Seriously as a Human Being [PhD dissertation]. Oslo: University of Oslo; 2014.

15. Ravneberg B, Söderström S. Disability, Society and Assistive Technology. London: Routledge; 2017.

16. WHOQOL Group. The World Health Organization Quality of Life assessment (WHOQOL): position paper from the World Health Organization. Soc Sci Med. 1995;41(10):1403-1409.

17. Eicher C, Haesner M, Spranger M, Kuzmicheva O, Gräser A, Steinhagen-Thiessen E. Usability and acceptability by a younger and older user group regarding a mobile robot-supported gait rehabilitation system. Assist Technol. 2017;16:1-9.

18. International Organization for Standardization. ISO 9241-110:2006. Ergonomics of Human-System Interaction. Geneva: ISO; 2006.

19. Cavallo F, Aquilano M, Arvati M. An ambient assisted living approach in designing domiciliary services combined with innovative technologies for patients with Alzheimer's disease: a case study. Am J Alzheimers Dis Other Demen. 2015;30(1):69-77.

20. Arthur WB. The Nature of Technology: What It Is and How It Evolves. London: Allen Lane; 2009.

21. Astell AJ, Ellis MP, Bernardi L, et al. Using a touch screen computer to support relationships between people with dementia and caregivers. Interact Comput. 2010;22(4):267-275.

22. Kenigsberg PA, Aquino JP, Bérard A, et al. Dementia beyond 2025 knowledge and uncertainties. Dementia (London). 2016;15(1):6-21.

23. Rosenberg L, Kottorp A, Nygård L. Readiness for technology use with people with dementia: the perspectives of significant others. $J$ Appl Gerontol. 2012;31(4):510-530.

24. Arntzen C, Holthe T, Jentoft R. Tracing the successful incorporation of assistive technology into everyday life for younger people with dementia and family carers. Dementia (London). 2016;15(4):646-662.

25. Moher D, Liberati A, Tetzlaff J, Altman DG; PRISMA Group. ReprintPreferred Reporting Items for Systematic Reviews and Meta-Analyses: the PRISMA statement. Phys Ther. 2009;89(9):873-880.

26. Pluye P, Robert E, Cargo M, et al. Proposal: A Mixed Methods Appraisal Tool for Systematic Mixed Studies Reviews. Montreal: McGill University; 2011. Available from: http://mixedmethodsappraisaltoolpublic.pbworks.com. Accessed August 29, 2016.

27. Hattink BJ, Meiland FJ, Overmars-Marx T, et al. The electronic, personalizable Rosetta system for dementia care: exploring the userfriendliness, usefulness and impact. Disabil Rehabil Assist Technol. 2016;11(1):61-71.
28. Meiland FJ, Bouman AI, Sävenstedt S, et al. Usability of a new electronic assistive device for community-dwelling persons with mild dementia. Aging Ment Health. 2012;16(5):584-591.

29. Meiland FJ, Hattink BJ, Overmars-Marx T, et al. Participation of end users in the design of assistive technology for people with mild to severe cognitive problems: the European Rosetta project. Int Psychogeriatr. 2014;26(5):769-779.

30. Lancioni G, Singh N, O’Reilly M, et al. Persons with mild and moderate Alzheimer's disease use verbal-instruction technology to manage daily activities: effects on performance and mood. Dev Neurorehabil. 2009;12(4):181-190.

31. Lancioni GE, Singh NN, O'Reilly MF, et al. Technology-aided verbal instructions to help persons with mild or moderate Alzheimer's disease perform daily activities. Res Dev Disabil. 2010;31(6):1240-1250.

32. Faucounau V, Riguet M, Orvoen G, et al. Electronic tracking system and wandering in Alzheimer's disease: a case study. Ann Phys Rehabil Med. 2009;52:579-587.

33. Pot AM, Willemse BM, Horjus S. A pilot study on the use of tracking technology: feasibility, acceptability, and benefits for people in early stages of dementia and their informal caregivers. Aging Ment Health. 2012;16(1):127-134.

34. Røhne M, Boysen E, Ausen D. Wearable and mobile technology for safe and active living. In: pHealth 2017. Proceedings of the 14th International Conference on Wearable, Micro \& Nano Technologies for Personalized Health, 14-16 May 2017, Eindhoven, The Netherlands. Amsterdam: IOS Press; 2017:133-139.

35. Chang YJ, Peng SM, Wang TY, Chen SF, Chen YR, Chen HC. Autonomous indoor wayfinding for individuals with cognitive impairments. J Neuroeng Rehabil. 2010;7:45.

36. Lanza C, Knörzer O, Weber M, Riepe MW. Autonomous spatial orientation in patients with mild to moderate Alzheimer's disease by using mobile assistive devices: a pilot study. J Alzheimers Dis. 2014; 42(3):879-884.

37. McCabe L, Innes A. Supporting safe walking for people with dementia: user participation in the development of new technology. Gerontechnology. 2013;12(1):4-15.

38. Augusto J, Mulvenna M, Zheng H, et al. Night optimised care technology for users needing assisted lifestyles. Behav Inf Technol. 2014; 33(12):1261-1277.

39. Rowe MA, Kelly A, Horne C, et al. Reducing dangerous nighttime events in persons with dementia by using a nighttime monitoring system. Alzheimers Dement. 2009;5(5):419-426.

40. Riikonen M, Mäkelä K, Perälä S. Safety and monitoring technologies for the homes of people with dementia. Gerontechnology. 2010; 9(1):32-45.

41. Robinson L, Brittain K, Lindsay S, Jackson D, Olivier P. Keeping In Touch Everyday (KITE) project: developing assistive technologies with people with dementia and their carers to promote independence. Int Psychogeriatr. 2009;21(3):494-502.

42. Boman IL, Nygård L, Rosenberg L. Users' and professionals' contributions in the process of designing an easy-to-use videophone for people with dementia. Disabil Rehabil Assist Technol. 2014;9(2):164-172.

43. Lindqvist E, Larsson TJ, Borell L. Experienced usability of assistive technology for cognitive support with respect to user goals. NeuroRehabilitation. 2015;36(1):135-149.

44. Malinowsky C, Almkvist O, Kottorp A, Nygård L. Ability to manage everyday technology: a comparison of persons with dementia or mild cognitive impairment and older adults without cognitive impairment. Disabil Rehabil Assist Technol. 2010;5(6):462-469.

45. Malinowsky $\mathrm{C}$, Almkvist $\mathrm{O}$, Nygård L, Kottorp A. Individual variability and environmental characteristics influence older adults' abilities to manage everyday technology. Int Psychogeriatr. 2012;24(3): 484-495.

46. Kerssens C, Kumar R, Adams AE, et al. Personalized technology to support older adults with and without cognitive impairment living at home. Am J Alzheimer Dis Other Demen. 2015;30(1):85-97. 
47. Leuty V, Boger J, Young L, Hoey J, Mihailidis A. Engaging older adults with dementia in creative occupations using artificially intelligent assistive technology. Assist Technol. 2013;25(2):72-79.

48. Lim FS, Wallace T, Luszcz MA, Reynolds KJ. Usability of tablet computers by people with early-stage dementia. Gerontology. 2013;59(2): 174-182.

49. Browne G, Berry E, Kapur N, et al. SenseCam improves memory for recent events and quality of life in a patient with memory retrieval difficulties. Memory. 2011;19(7):713-722.

50. de Oliveira Assis L, Tirado MG, de Melo Pertence AE, Pereira LS, Mancini MC. Evaluation of cognitive technologies in geriatric rehabilitation: a case study pilot project. Occup Ther Int. 2010;17(2):53-63.

51. Suijkerbuijk S, Brankaert R, de Kort YA, Snaphaan LJ, den Ouden E. Seeing the first-person perspective in dementia: a qualitative personal evaluation game to evaluate assistive technology for people affected by dementia in the home context. Interact Comput. 2015;27(1):47-59.

52. Wu YH, Cristancho-Lacroix V, Fassert C, Faucounau V, de Rotrou J, Rigaud AS. The attitudes and perceptions of older adults with mild cognitive impairment toward an assistive robot. J Appl Gerontol. 2016; 35(1):3-17.

53. Mehrabian S, Extra J, Wu YH, Pino M, Traykov L, Rigaud AS. The perceptions of cognitively impaired patients and their caregivers of a home telecare system. Med Devices (Auckl). 2015;8:21-29.

54. Gibson G, Newton L, Pritchard G, Finch T, Brittain K, Robinson L. The provision of assistive technology products and services for people with dementia in the United Kingdom. Dementia (London). 2016;15(4): 681-701.

55. McCreadie C, Tinker A. The acceptability of assistive technology to older people. Ageing Soc. 2005;25(1):91-110.

56. Peek STM, Wouters EJM, van Hoof J, Luijkx KG, Boeije HR, Vrijhoef HJM. Factors influencing acceptance of technology for aging in place: a systematic review. Int J Med Inform. 2014;83:235-248.

57. Hedman A, Lindqvist E, Nygård L. How older adults with mild cognitive impairment relate to technology as part of present and future everyday life: a qualitative study. BMC Geriatr. 2016;16:73.

58. Peek STM, Aarts S, Wouters EJM. Can smart home technology deliver on the promise of independent living? In: van Hoof J, Deniris G, Wouters E, editors. Handbook of Smart Homes, Health Care and WellBeing. Cham: Springer; 2016:203-214.
59. Rubin J. Handbook of Usability: How to Plan, Design and Conduct Effective Tests. New York: John Wiley \& Sons; 1994.

60. European Working Group of People with Dementia. Nothing about us without us. In: 23rd Alzheimer Europe Conference, St. Julian's, Malta, October 2013. Available from: http://www.alzheimer-europe.org/Conferences/ Previous-conferences/2013-St-Julian-s/Detailed-programme-abstractsand-presentations/SS1.-Nothing-about-us-without-us. Accessed January 9, 2018.

61. Creswell JW. Research Design. Qualitative, Quantitative, and Mixed Method Approaches. 4th ed. Thousand Oaks: Sage; 2014.

62. Demers L, Weiss-Lambrou R, Ska B. The Quebec User Evaluation of Satisfaction with Assistive Technology (QUEST 2.0): an overview and recent progress. Technol Disabil. 2002;14:101-105.

63. Swarthmore College Computer Society. Technology definitions. www.sccs.swarthmore.edu/users/97/jahall/thesis/tech/actpassive.html. Accessed January 9, 2018.

64. EU-project ENABLE QLK6-CT-2000-00653 (2001-2004) National reports from assessment studies in UK, Finland, Norway and Lithuania. Available from: Enable. www.enableproject.org. Accessed May 22, 2017.

65. Woolham J, Frisby B. How technology can help people feel safe at home. Available from: https://www.researchgate.net/publication/292541867. Accessed May 22, 2017.

66. Magnusson L, Berthold H, Chambers M, Brito L, Emery D, Daly T. Using telematics with older people: the ACTION project. Assisting Carers using Telematics Interventions to meet Older persons' Needs. Nurs Stand. 1998;13(5):36-40.

67. Meiland FJ, Reinersmann A, Sävenstedt S, et al. User-participatory development of assistive technology for people with dementia - from needs to functional requirements. First results of the COGKNOW project. Non-Pharmacological Therapies in Dementia. 2010;1(1):71-90.

68. Alberdi A, Weakley A, Schmitter-Edgecombe M, et al. Smart Homes predicting the Multi-Domain Symptoms of Alzheimer's Disease. IEEE $J$ of biomedical and health informatics. 2018. Available from: http:// eecs.wsu.edu/ cook/pubs/jbi18.pdf. Accessed March 19, 2018.

69. Augusto JC, Zheng H, Mulvenna M, Wang H, Carswell W, Jeffers P. Design and Modelling of the Nocturnal AAL Care System. Ambient Intelligence - Software and Applications. 2011;92:109-116.
Clinical Interventions in Aging

\section{Publish your work in this journal}

Clinical Interventions in Aging is an international, peer-reviewed journal focusing on evidence-based reports on the value or lack thereof of treatments intended to prevent or delay the onset of maladaptive correlates of aging in human beings. This journal is indexed on PubMed Central, MedLine,

\section{Dovepress}

CAS, Scopus and the Elsevier Bibliographic databases. The manuscript management system is completely online and includes a very quick and fair peer-review system, which is all easy to use. Visit http://www.dovepress. com/testimonials.php to read real quotes from published authors. 